\title{
A ATUAÇÃO DOS GRUPOS DE INTERESSE NAS CONSULTAS E AUDIÊNCIAS PÚBLICAS DA AGÊNCIA NACIONAL DE SAÚDE SUPLEMENTAR (ANS)
}

\section{THE PARTICIPATION OF INTEREST GROUPS IN NOTICE-AND- COMMENT AND PUBLIC HEARING PROCEDURES AT THE NATIONAL AGENCY FOR PRIVATE INSURANCE (ANS)}

\author{
NATASHA SCHMITT CACCIA SALINAS ${ }^{1}$
}

RESUMO: Este artigo tem por objetivo analisar a influência dos grupos de interesse nos processos decisórios da Agência Nacional de Saúde Suplementar (ANS). Grupos de interesse podem ser definidos como reuniões de pessoas que atuam, de forma coordenada, para influenciar uma decisão governamental. Neste artigo, analisa-se dois meios específicos pelos quais grupos de interesse agem para influenciar a tomada de decisão das agências reguladoras: as consultas e audiências públicas. As agências reguladoras estão obrigadas, por força de lei, a realizarem consultas públicas antes de editarem atos normativos e podem, facultativamente, realizar consultas e audiências públicas previamente a qualquer tomada de decisão. Neste artigo, propõe-se a identificar quem são os grupos de interesse que mais participam das consultas públicas da ANS, bem como examinar a influência desta participação no conteúdo final da decisão tomada pela agência. Para responder a essas questões, foram utilizados dados das consultas e audiências públicas realizadas pela agência entre 2001 e 2019, extraídos da base de dados do projeto Regulação em Números da FGV Direito Rio. Ao término do artigo, será possível identificar se e em que medida a atuação dos grupos de interesse na ANS está alinhada com a literatura empírica nacional e estrangeira.

Palavras-Chave: Grupos de Interesse; Agência Nacional de Saúde Suplementar; Consulta Pública; Audiência Pública; Mecanismos de Participação.

\footnotetext{
${ }^{1}$ Professora do Programa de Pós-graduação (Mestrado e Doutorado) em Direito da Regulação e do curso de graduação em Direito da FGV Direito Rio. Doutora e Mestre em Direito pela USP. Master of Laws (LL.M.) pela Yale Law School.
} 
ABSTRACT: This article aims to analyze the influence of interest groups in the decision-making processes at the National Agency for Private Health Insurance (ANS). Interest groups can be described as organized efforts to influence government decision-making. This article analyzes two mechanisms under which interest groups act to influence regulatory decision-making: notice-and-comment and public hearing procedures. Regulatory agencies are required by law to conduct notice-and-comment rulemaking and have the discretion to promote notice-andcomment and public hearings in any sort of decision-making. This article identifies which interest groups participate more actively in these participation mechanisms and examines the extent to which their comments alter the content of ANS's decisions. For answering these questions, I used data of notice-and-comments and public hearings held by ANS from 2001 to 2019, which were extracted from a database of the Regulation by Numbers project at FGV Direito Rio. The article concludes by demonstrating to which extent interest groups behave in line with the findings of the national and international empirical literature.

KEYWORDS: Interest Groups; National Agency for Private Health Insurance; Noticeand-Comment; Public Hearing; Participation Mechanisms.

\section{INTRODUÇÃO}

Este artigo tem por objetivo analisar a influência de grupos de interesse nos processos normativos das agências reguladoras independentes. Grupos de interesse podem ser definidos como reuniões de pessoas que atuam, de forma coordenada, para influenciar uma decisão governamental (KERWIN; FURLONG, WEST, 2011, p. 1). Os canais de atuação dos grupos de interesse são os mais diversos e incidem sobre todos os poderes - do legislativo ao judiciário. Há, no entanto, uma prevalência de estudos sobre a atuação de grupos de interesse nas arenas legislativas, em especial no Congresso Nacional (MANCUSO, 2007; SANTOS, 2011).

Neste artigo, pretende-se analisar a influência de grupos de interesse nos processos decisórios das agências reguladoras. Estudos desta natureza são incipientes no Brasil. ${ }^{2}$ Os amplamente difundidos modelos teóricos sobre a relação entre grupos de interesse e burocracia, como as teorias da captura (BERNSTEIN, 1955, STIGLER, 1975; BAGLEY, 2010), por exemplo, ainda não estão lastreados por quantidade suficiente de estudos empíricos no país. Em parte, isto se deve ao fato de que as agências reguladoras independentes atuam há apenas duas décadas no Brasil. Até recentemente, não havia uma lei que disciplinasse os processos decisórios das agências, sendo estes regidos essencialmente por normas regimentais (SALINAS; MARTINS, 2018, p. 348).

De todo modo, as leis-quadro que criaram as agências reguladoras e a recente Lei n. 13.848/19, usualmente referida como "Lei Geral das Agências Reguladoras",

${ }^{2}$ Há exceções dignas de nota, que serão oportunamente mencionadas neste artigo. 
transplantaram para o Brasil um desenho institucional no qual grupos de interesse participam formalmente dos processos decisórios das agências, especialmente dos processos de produção normativa.

Esses processos decisórios são participativos, na medida que exigem a realização de consulta pública para discutir minutas de atos normativos que afetem direitos ou instituam obrigações de agentes econômicos regulados e usuários dos serviços regulados. Embora a Lei Geral das Agências Reguladoras só obrigue a realização de consulta para os casos de produção de normas, este mecanismo de participação é também usualmente utilizado pelas agências em etapas prénormativas, seja para a formulação de sua agenda regulatória, seja para decidir se deverá ou não regular determinada matéria. ${ }^{3}$

As agências reguladoras podem facultativamente realizar audiências públicas, as quais poderão ou não estar associadas às consultas públicas. Audiências públicas são reuniões presenciais e constituem, portanto, um outro meio de participação formal mediante o qual grupos de interesse podem participar dos processos decisórios das agências. ${ }^{4}$

Nos processos de consulta e audiência pública, qualquer pessoa interessada, física ou jurídica, nacional ou estrangeira, pode apresentar contribuições por escrito para o aperfeiçoamento das normas sob discussão. Estas pessoas filiam-se a grupos de interesse diversos, com destaque para os agentes econômicos diretamente regulados pelas agências, os usuários dos serviços ou consumidores de produtos regulados e representantes da própria burocracia governamental. ${ }^{5}$ Há, também, outros grupos que possuem interesse na atuação regulatória das agências, como agentes econômicos não diretamente regulados por determinado órgão governamental, mas que fornecem bens ou serviços para as empresas reguladas.

Este artigo se propõe a examinar a influência dos grupos de interesse nas consultas e audiências públicas realizadas pela Agência Nacional de Saúde Suplementar (ANS). A ANS é uma autarquia constituída sob regime especial, vinculada ao Ministério da Saúde, com autonomia administrativa, financeira, patrimonial, decisória e de gestão de recursos humanos, vinculada ao Ministério da Saúde (BRASIL, 2000). Esta agência foi criada com o condão de ser o órgão regulador, normatizador, controlador e fiscalizador das atividades que garantem a assistência suplementar à saúde.

$\mathrm{O}$ artigo analisa quem são os grupos de interesse que mais participam das consultas públicas da ANS, bem como examina a influência dessa participação no conteúdo final da decisão tomada pela agência.

\footnotetext{
${ }^{3}$ Nas agências reguladoras de serviços públicos, as consultas e audiências públicas são também utilizadas para discutir editais de licitação e minutas de contratos administrativos, especialmente de contratos de concessão.

${ }^{4}$ Algumas agências adotam outros meios de participação formal, como tomadas de subsídios, reuniões participativas etc.

${ }^{5}$ Neste artigo, entes governamentais são tratados como um grupo de interesse próprio, que guarda especificidades em relação aos agentes econômicos regulados e às entidades consumeristas.
} 
A ANS vem realizando consultas públicas desde 2001 e audiências públicas desde 2014. De 2011 a 2019, a agência adotou 89 mecanismos de participação em seus processos de tomada de decisão, dos quais 74 foram consultas públicas e 15 audiências públicas (CPDE, 2020f). Até a criação da Lei Geral das Agências Reguladoras, consultas públicas eram realizadas pela ANS de forma discricionária, sendo que a agência adotou este mecanismo de participação para a produção de apenas 10,9\% de suas normas (CPDE, 2020f). As análises apresentadas neste artigo baseiam-se na extração e codificação, com suporte do projeto Regulação em Números da FGV Direito Rio, de dados constantes dos relatórios de análise de contribuições disponibilizados pela agência em seu site. Dentre as principais variáveis analisadas estão as categorias de grupos de interesse dos participantes e o percentual de aceitação e rejeição das contribuições realizadas por estes grupos nas consultas e audiências públicas.

Este artigo subdivide-se em cinco partes, para além de sua introdução e conclusão. Na primeira, revisa-se a literatura norte-americana e brasileira sobre a atuação dos grupos de interesse nos processos normativos das agências reguladoras. Na segunda parte, apresenta-se a metodologia utilizada para a análise empírica dos mecanismos de participação da ANS. Na terceira, descreve-se os principais grupos de interesse atuantes no setor de saúde suplementar. Por fim, na quarta e quinta parte, busca-se responder às duas principais questões apresentadas neste artigo: quais são os grupos de interesse que mais participam das consultas e audiências públicas da ANS e qual é a influência de sua participação na tomada decisão desta agência. Ao término do artigo, será possível identificar se e em que medida a atuação dos grupos de interesse na ANS está alinhada com a literatura empírica nacional e estrangeira.

\section{A AtuAÇÃo dos grupos de INTERESSE NAS CONSUltAS E AUDiÊNCIAS PÚbLICAS}

São recentes os estudos sobre a atuação dos grupos de interesse nos processos decisórios das agências reguladoras. A literatura é recente até mesmo nos Estados Unidos, onde as consultas públicas, denominadas de notice-and-comment procedures, são exigidas nos processos de produção normativa das agências desde 1946, quando o Administrative Procedure Act foi instituído. ${ }^{6}$

A partir da década de 1990, estudos empíricos desenvolvidos nos Estados Unidos confirmaram que os agentes econômicos diretamente regulados pelas agências são aqueles que mais participam das consultas públicas. Este dado foi confirmado por surveys com grupos de interesse diversos (FURLONG; KERWIN; 2005), bem como por estudos que analisaram os comentários desses grupos em processos normativos diversos (GOLDEN, 1998; YACKEE, 2006; YACKEE e YACKEE, 2006). No entanto, a predominância da participação dos agentes

\footnotetext{
${ }^{6}$ Algo que pode ter retardado o desenvolvimento desta literatura nos Estados Unidos diz respeito ao fato de que as consultas eram originalmente manuais ou físicas. No Brasil, as primeiras consultas públicas realizadas por agências reguladoras ocorreram após o surgimento da internet (KERWIN; FURLONG, 2019, p 188-192).
} 
econômicos regulados nos processos regulatórios nos Estados Unidos não exclui a participação, frequentemente estratégica, de outros grupos de interesse diretamente afetados pela regulação, como aqueles representados por entidades consumeristas (FRITSCHLER, 1989; CHEIT, 1990) e ambientalistas (MAGAT, KRUPNICK, HARRINGTON, 2011).

Ressalvas podem ser feitas, no entanto, quanto ao alcance das inferências realizadas nesses estudos, já que o conjunto de processos normativos analisados é irrisório diante do excessivo volume de estoque regulatório produzido pelas agências governamentais nos Estados Unidos.

O estudo de Silva (2012), que examinou o universo total de audiências públicas ${ }^{7}$ realizadas pela Aneel entre 1998 e 2006, identificou uma predominância dos agentes econômicos regulados nas audiências públicas da Aneel. Os agentes regulados, denominados pela autora de "produtores", representaram 47,31\% do universo total de participantes das audiências públicas e foram os responsáveis por $73,47 \%$ de todas as contribuições realizadas. Os consumidores foram o segundo maior grupo, representando $22,49 \%$ de todos os participantes das audiências públicas. Com base em Wilson (1989) e Olson (1999), Silva (2012) defende que os agentes econômicos regulados possuem maiores incentivos para participar das audiências na medida que a regulação concentra benefícios nestes agentes e dilui os custos entre os consumidores.

Estudos desenvolvidos no âmbito do projeto Regulação em Números têm mostrado que este fenômeno é observado apenas para parte das agências reguladoras. Agentes econômicos regulados representam o grupo de interesse mais participativo de agências como Aneel (CPDE, 2020e), Ana (CPDE, 2020a), Ancine (CPDE, 2020d), CVM (CPDE, 20201) e Antaq (CPDE, 2020g). No entanto, nos processos decisórios de agências como Anac (CPDE, 2020b), ANTT (CPDE, 2020h), Bacen (CPDE, 2020j) e Anvisa (CPDE, 2020i), pessoas físicas participam em maior número do que os agentes regulados.

Os grupos de interesse que mais participam podem ou não ser aqueles que mais influenciam o processo regulatório. Por influência entende-se a capacidade que determinado grupo de interesse possui em ter suas contribuições aceitas pela agência reguladora após a realização da consulta pública. Uma agência não está obrigada a aceitar uma contribuição que receba no transcorrer de seus mecanismos participativos, bastando que motive sua decisão, manifestando se acolhe ou não a contribuição recebida. ${ }^{8}$ As contribuições aceitas pela agência reguladora servem, portanto, de proxies para medir a influência dos grupos de interesse.

\footnotetext{
${ }^{7}$ A Aneel denominava de audiência pública tanto mecanismos de participação presenciais quanto não presenciais. Foi apenas com o advento da Lei Geral das Agências Reguladoras que mecanismos presenciais passaram a ser denominados de consulta pública.

${ }^{8}$ No caso brasileiro, o ônus argumentativo das decisões das agências em seus mecanismos de participação é fraco. Embora a Lei de Processo Administrativo (BRASIL, 1999) estabeleça o dever da Administração de motivar suas decisões, não há sanções previstas no caso de ausência de
} 
A literatura americana tem revelado que o setor regulado, além de ser aquele que mais participa, é também aquele que mais influencia o processo regulatório, especialmente quando sua participação se dá em momento anterior à formulação da norma. A influência do setor regulado parece ser especialmente decisiva quando sua participação se dá no momento de formação da agenda regulatória ou de tomada de subsídios anterior à formulação do texto normativo (NAUGHTON et all, 2009; WEST, 2004). A influência do setor regulado, por sua vez, diminui quando sua participação se dá em momento avançado do processo decisório da agência.

De todo modo, tanto a literatura estrangeira quanto a nacional confirmam que grupos de interesse diversos influenciam o processo de tomada de decisão das agências mesmo em fases mais avançadas do processo normativo. No estudo envolvendo a Aneel, Silva (2012) identificou que 40,1\% das contribuições realizadas pelos agentes regulados foram aceitas e 50,6\% foram rejeitadas. ${ }^{9}$ Já os consumidores tiveram $35,6 \%$ de suas contribuições aceitas ou parcialmente aceitas e $50,2 \%$ rejeitadas, sendo que os pedidos de esclarecimento totalizaram $9,9 \%$. Neste estudo, no entanto, não foi possível observar um favoritismo do setor regulado para influenciar o processo regulatório, já que o percentual de contribuições aceitas e parcialmente aceitas era apenas ligeiramente superior ao percentual de aceitação das manifestações do grupo de consumidores. Além disso, cerca de 50\% das contribuições realizadas por ambos os grupos foram rejeitadas pela agência reguladora. Em estudo realizado com a Anac, Baird e Fernandes (2014) identificaram 53,7\% de aceitação das contribuições dos atores governamentais, $49,6 \%$, de aceitação das manifestações do setor regulado e $27,7 \%$ de aprovação das propostas de indivíduos interessados (BAIRD; FERNANDES, 2014). Nesta pesquisa os autores identificaram um certo favoritismo dos atores governamentais para influenciar o processo regulatório da Anac, fenômeno este também observado em outras agências como Anvisa (CPDE, 2020i) e Aneel (CPDE, 2020e).

Sobre o tipo de influência que é exercida pelos grupos de interesse no processo regulatório das agências, Golden (1998) concluiu que quando não há consenso entre os participantes de uma consulta pública em estágios mais avançados do processo normativo, a agência tende a considerar apenas as contribuições que estão alinhadas com sua posição inicial. Yackee (2006) observou que as agências tendem a aceitar as contribuições que atingem maior consenso entre os participantes. Yackee e Yackee (2006) encontraram evidências de que as sugestões do setor regulado, que tendem a enfrentar o conteúdo propriamente dito das normas, exercem maior influência no processo regulatório. Em linha semelhante, Baird e Fernandes (2014) identificaram que a Anac tende a incorporar em níveis mais acentuados sugestões de caráter técnico, independentemente delas terem sido propostas pelo setor regulado ou por atores governamentais. Os autores concluem que o favoritismo nas contribuições destes grupos de interesse se deve

motivação. Na prática há significativa variação no modo como as agências motivam, quando o fazem, suas decisões no curso dos mecanismos de participação.

${ }_{9}^{9} \mathrm{O}$ restante das contribuições, equivalente a 9,2\% do total, refere-se a pedidos de esclarecimentos. 
exclusivamente ao fato de que seus comentários são mais técnicos do que as sugestões propostas por outros grupos.

Embora tenham avançado no conhecimento sobre a atuação e influência dos grupos de influência nos processos decisórios das agências, as conclusões destes estudos nem sempre são generalizáveis, dadas as especificidades de cada setor regulado. É por este motivo que aqui se propõe a analisar especificamente o caso da ANS.

\section{Coleta e anÁlise de dados}

Para a resolução dos problemas de pesquisa deste artigo, foram analisados dados referentes aos mecanismos de participação realizados pela agência entre 2001 e 2019, que corresponderam a 74 consultas públicas e 15 audiências públicas. Utilizou-se, para tanto, a base de dados sobre mecanismos de participação construída no âmbito do projeto Regulação em Números da FGV Direito Rio ${ }^{10}$. Esta base de dados tem como unidade de análise a pessoa que participa do mecanismo de participação. Nesta base, são identificadas variáveis que informam o nome, a personalidade jurídica (quando houver), e o grupo de interesse ao qual pertence o contribuinte, bem como o impacto de suas contribuições no resultado do mecanismo de participação. Foi elaborada, para a ANS, uma classificação própria de categorias de participantes, mas o desenho das categorias seguiu alguns padrões comuns a todas as agências reguladoras, de forma a permitir comparações futuras. Em todas as agências, foi identificado se o contribuinte era uma pessoa física ou não, se era diretamente regulado pela agência ou não, se tratava de um ator governamental ou não, e se se tratava de uma entidade representativa de interesses ou não.

Para análise do impacto das contribuições, o projeto estabeleceu convenções metodológicas cujo objetivo foi preservar a coerência e consistência dos dados levantados diante da diversidade intrínseca ao objeto estudado. Para fins deste estudo, o impacto das contribuições das manifestações dos grupos de interesse é medido a partir das respostas oferecidas pela agência que constam dos relatórios oficiais publicados em seu site. Para medir o impacto, portanto, somam-se as respostas que acatam e as que rejeitam as contribuições de cada contribuinte. Está excluída da análise do impacto aqui pretendida a verificação se de fato a contribuição foi incorporada ao texto normativo ou qualquer outra tomada de decisão da agência.

\footnotetext{
${ }^{10} \mathrm{O}$ "Regulação em Números" é um projeto institucional da FGV Direito Rio, que tem por objetivo desenvolver estudos empíricos sobre agências reguladoras federais. Desenvolvido no âmbito do Centro de Pesquisa em Direito e Economia (CPDE) da FGV Direito Rio, o Regulação em Números atualmente desenvolve quatro frentes de pesquisa principais: (i) Mecanismos de Participação (audiências e consultas públicas) das agências reguladoras federais; (ii) processo administrativo normativo das agências; (iii) Controle político/legislativo das agências reguladoras; (iv) Controle judicial e externo das agências reguladoras.
} 
Os dados da base utilizada nesta pesquisa foram extraídos dos relatórios de análise de contribuições das consultas e audiências públicas, publicados no portal eletrônico da ANS. Dois tipos de relatórios são produzidos pela agência: (i) um relatório completo, em que é possível identificar dados pessoais dos contribuintes, o conteúdo de suas contribuições, bem como as respostas individualizadas da agência; (ii) um relatório síntese, em que a agência informa o total de contribuições recebidas, bem como o índice de aceitação e rejeição dessas manifestações. Em alguns desses relatórios síntese, a agência informa os percentuais de manifestações provenientes de cada grupo de interesse específico.

A ANS produziu e publicou relatório completo de análise de contribuições em apenas 26 dos 89 mecanismos que realizou, equivalente a 29,2\% dos casos, conforme mostra o gráfico 1. Já o número de relatórios-síntese é maior: 55 de 89 , equivalente a $61,8 \%$ dos casos, como se verifica no gráfico $2 .{ }^{11}$

\section{Gráfico 1 \\ Disponibilidade de relatórios completos de análise de contribuições}

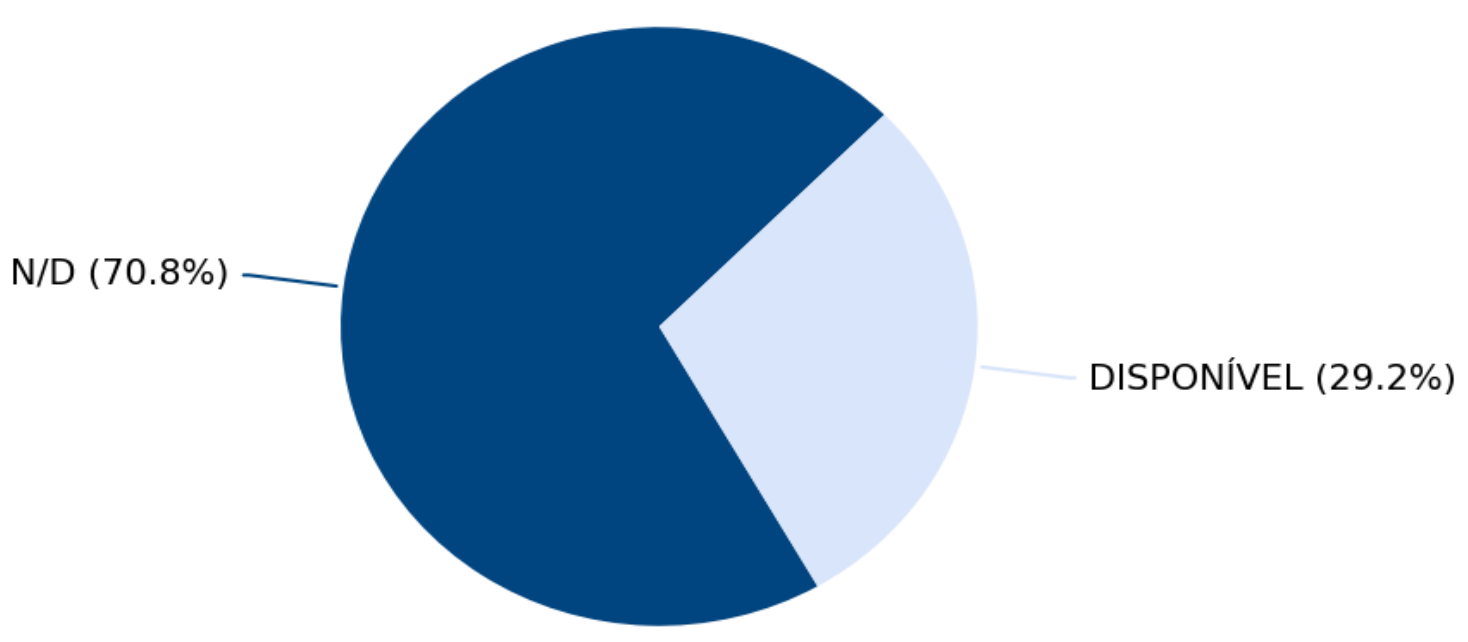

Fonte: elaboração própria a partir de base de dados do Regulação em Números

\footnotetext{
${ }^{11}$ Em estudo anterior (SALINAS; MARTINS, 2018), observou-se que a ANS não se considera obrigada a publicar relatório completo, em que informa o número e identidade de todos os participantes. Isto explica a publicação predominante de relatórios-síntese pela agência.
} 


\section{Gráfico 2}

\section{Disponibilidade de relatórios-síntese de análise de contribuições}

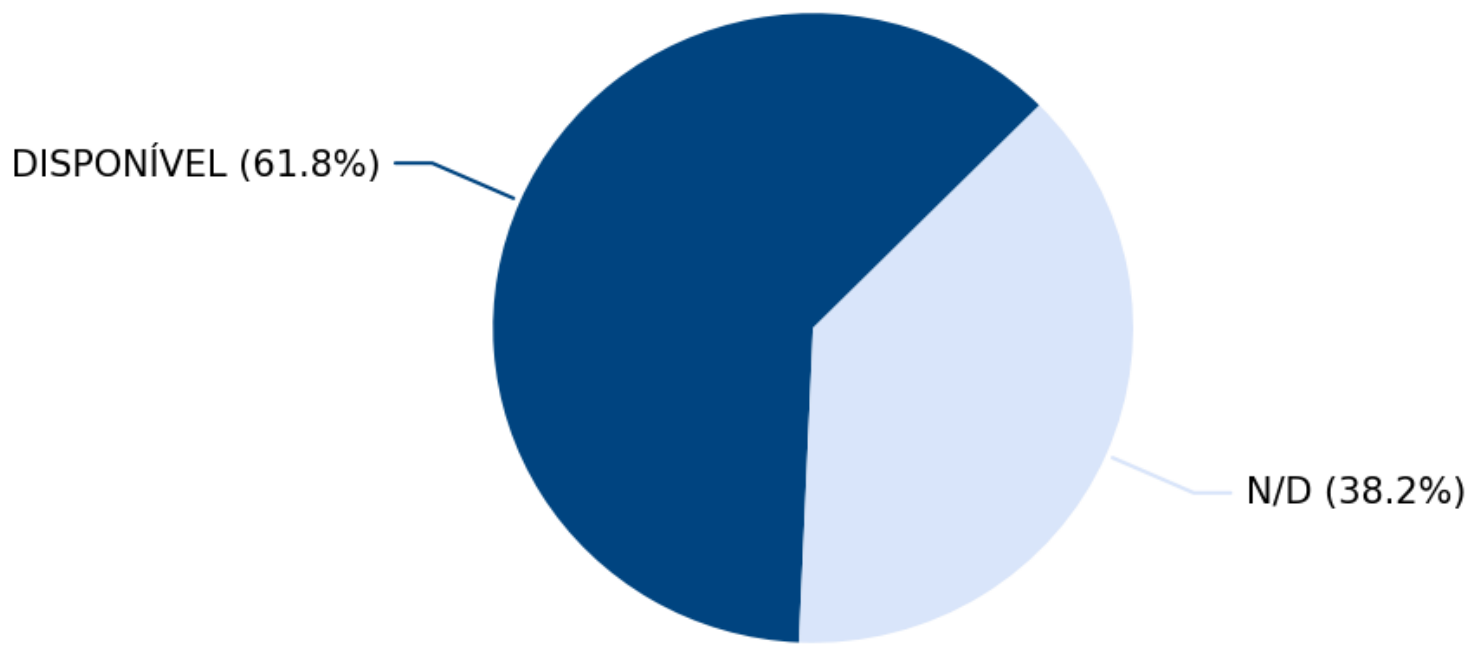

Fonte: elaboração própria a partir de base de dados do Regulação em Números

A indisponibilidade de relatórios gera limitações a esta pesquisa. Os documentos mais completos e claros são aqueles que respondem de forma objetiva a cada contribuição oferecida, deixando evidente para os pesquisadores se as sugestões de cada contribuinte foram ou não acatadas pela agência. As respostas individualizadas das contribuições são fundamentais para que os pesquisadores possam saber se a agência acatou ou não as sugestões do contribuinte e, em caso negativo, por quê sua contribuição não foi aceita. Nesse sentido, um problema recorrente em vários relatórios de análise de contribuição é a impossibilidade de se identificar o grupo de interesse nos casos em que do autor da proposta quando a agência disponibiliza apenas o número do protocolo da contribuição. Deste modo, os números de participantes e de contribuições abaixo apresentados correspondem a uma amostra não aleatória, podendo, assim, estar sub ou sobrerepresentados.

\section{CATEGORIAS DE PARTICIPANTES DAS CONSUlTAS E AUDIÊNCIAS PÚBLICAS DA ANS}

Qualquer pessoa interessada, física ou jurídica, brasileira ou estrangeira, poderá participar de uma audiência pública ou consulta pública conduzida pela ANS.

Os motivos pelos quais estas pessoas participam dos mecanismos de participação da ANS são variados, dada a pluralidade de interesses e grupos que representam. Neste estudo, foi possível identificar as seguintes categorias de participantes analisadas a seguir. 


\subsection{Agente econômico regulado (operadoras) e suas entidades representativas}

Os agentes econômicos regulados pela ANS são aqueles que atuam na assistência suplementar à saúde: as operadoras de plano de saúde e, ainda, suas entidades representativas. Atualmente, há cerca de 800 operadoras em atuação no país ${ }^{12}$ que ofertam serviços a cerca de $25 \%$ da população brasileira. As operadoras organizam-se sob a forma de cooperativas médicas e odontológicas, empresas de medicina de grupo, seguradoras, autogestoras, entidades filantrópicas e administradoras de benefícios (BRASIL, 2000).

As cooperativas de saúde, empresas de medicina de grupo e seguradoras de saúde dominam o mercado de saúde suplementar (BAIRD, 2017, p. 105).

As cooperativas de saúde, que atendem o maior número de beneficiários, são organizações cujos sócios são ao mesmo tempo administradores do plano e prestadores de serviço. As cooperativas médicas e odontológicas regem-se pela Lei n. 5.764, de 16 de dezembro de 1971 (BRASIL, 1971). As primeiras operam planos privados de assistência à saúde e as segundas operam planos odontológicos. A Unimed, que se organiza em unidades municipais, é a maior cooperativa médica do Brasil. As cooperativas Unimed são representadas por federações estaduais e por uma confederação nacional - a Unimed do Brasil.

Já as empresas de medicina de grupo caracterizam-se por ofertar planos coletivos e/ou individuais para empresas, famílias e indivíduos. Amil é a empresa médica de grupo com maior faturamento no Brasil. A Associação Brasileira de Medicina de Grupo (Abramge) e o Sindicato Nacional das Empresas de Medicina de Grupo (Sinamge) são duas importantes entidades representativas das empresas deste segmento. Empresas de medicina de grupo lideram o setor, ocupando 31\% do mercado de planos de saúde (BAIRD, 2017, p. 74).

As seguradoras de saúde, vinculadas muitas vezes a bancos, ${ }^{13}$ atuam de forma semelhante às empresas de medicina de grupo e cooperativas, na medida que comercializam planos de saúde mediante oferta referenciada, com pagamento direto ao prestador.

O quarto grupo de maior faturamento é o das autogestoras (BAIRD, 2017, p. 105). Estas são entidades que fornecem diretamente os serviços médicos aos seus próprios funcionários. ${ }^{14}$ Cassi e Geap Autogestão em Saúde, por exemplo, são

${ }^{12}$ O setor de saúde suplementar vem se tornando cada vez mais concentrado. Em 1999, ano em que foi instituído o novo regime jurídico do setor, havia cerca de 1.380 operadoras em atividade no país. Em 2016, embora existissem cerca de 800 operadoras no país, apenas $10 \%$ delas concentravam 72\% dos beneficiários de planos do país (BAIRD, 2017, p. 103).

${ }^{13}$ Bradesco Saúde e a SulAmérica são protagonistas deste segmento. Até 2007, a Federação Nacional das Empresas de Seguros Privados e de Capitalização (Fenaseg) foi a principal entidade representativa deste segmento. Esta entidade desmembrou-se em várias entidades representativas de seguros, sendo que a representação da área de saúde suplementar passou a ser exercida pela Federação Nacional de Saúde Suplementar (Fenasaúde).

${ }^{14}$ A ANS define a autogestora como "pessoa jurídica de direito privado que, por intermédio de seu departamento de recursos humanos ou órgão assemelhado, opera plano privado de assistência à saúde exclusivamente a beneficiários" (BRASIL, 2006). 
operadoras desta modalidade. A União Nacional das Instituições de Autogestão em Saúde (Unidas) é a principal entidade representativa deste segmento.

Já as administradoras de benefícios contratam planos coletivos para outras empresas, órgãos públicos ou entidades representativas profissionais. As administradoras de benefícios diferenciam-se de todas as anteriores por não possuírem beneficiários diretos (como as de autogestão), tampouco rede de prestadores própria, credenciada ou referenciada (como as empresas de medicina de grupo, cooperativas, filantrópicas e seguradoras. ${ }^{15}$ A Qualicorp é a principal empresa do setor e a Associação Nacional das Administradoras de Benefícios (Anab) é a principal entidade representativa deste segmento.

Por fim, as entidades filantrópicas são aquelas sem fins lucrativos que operam planos privados de assistência à saúde. Para que possam atuar como operadoras, estas entidades devem obter certificado de entidade beneficente de assistência social (Cebas) emitido pelo ministério competente (BRASIL, 2000, art. 17).

Antes da aprovação das leis que instituíram um regime regulatório para os planos de saúde (BRASIL, 1998; BRASIL, 2000b), as operadoras estavam sujeitas a regulamentações esparsas e distintas. ${ }^{16}$ Com a aprovação da Lei dos Planos de Saúde (BRASIL, 1998), introduziu-se um regime regulatório único que instituiu deveres e obrigações comuns a todas as modalidades de operadoras. ${ }^{17}$ No entanto, dadas as peculiaridades de cada segmento, este regime não é homogêneo e não se aplica indistintamente a todas as modalidades de operadoras.

\subsection{Agente econômico não regulado e suas entidades representativas}

Os agentes econômicos não regulados são os contribuintes que desempenham atividade econômica empresarial 18 não diretamente regulada pela ANS. Enquadram-se nesta categoria os prestadores de serviços de saúde, bem como os fornecedores de insumos e produtos de saúde. O sistema de saúde suplementar regula, portanto, quem financia a saúde complementar e não quem a produz.

\footnotetext{
${ }^{15}$ A administradora de benefícios é definida como "a pessoa jurídica que propõe a contratação de plano coletivo na condição de estipulante ou que presta serviços para pessoas jurídicas contratantes de planos privados de assistência à saúde coletivos" (BRASIL, 2009).

${ }^{16}$ As cooperativas de saúde, por exemplo, deveriam observar normas do Ministério da Agricultura, ao passo que as seguradoras de saúde se submetiam exclusivamente às regras da Susep. As entidades de autogestão estavam sujeitas a normas diluídas entre os Ministérios da Fazenda, Previdência e Trabalho, ao passo que as empresas de Medicina de Grupo não se sujeitavam a nenhum tipo de regulamentação (BAIRD, 2017, p. 79).

${ }^{17}$ Optou-se pela construção de um modelo regulatório único diante da visão de que as operadoras, não obstante suas diferenças operacionais, estariam ofertando um mesmo produto - a saúde (BAIRD, 2017, p. 91).

${ }^{18}$ A definição de "empresário" (atividade empresarial) oferecida pelo Código Civil Brasileiro (art. 966 do Código Civil Brasileiro) é aqui satisfatória para qualificar agente econômico não regulado. Enquadram-se nesta categoria, portanto, aquelas organizações que "exercem profissionalmente atividade econômica organizada para a produção ou a circulação de bens ou de serviços", sem, no entanto, utilizar a água de modo que justifique intervenção do órgão regulador.
} 
Os prestadores de serviços podem atuar tanto individualmente, na condição de pessoa física, quanto coletivamente, por meio de organizações com ou sem finalidade lucrativa.

As pessoas físicas que prestam serviços privados de saúde, como médicos e dentistas costumam participar das consultas e audiências públicas da ANS por meio de suas entidades representativas. A Associação Médica Brasileira ("AMB"), os Conselhos Federal de Medicina e de Odontologia ("CFM" e "CFO", respectivamente), bem como diversos conselhos federais e regionais de profissionais da área de saúde, são exemplos de entidades representativas que participam das consultas e audiências públicas da ANS.

Já as entidades prestadoras de serviços participam tanto individualmente quanto por meio de suas entidades representativas. Exemplos de entidades que representam os prestadores são a Confederação Nacional de Saúde ("CNS"), a Federação Brasileira de Hospitais ("FBH"), a Associação Nacional de Hospitais Privados ("Anahp") e a Associação Brasileira de Medicina Diagnóstica ("Abramed").

Além dos prestadores, outros agentes econômicos, como grupos empresariais de seguros e empresas comercializadoras de equipamentos médicos, também participam dos mecanismos como, por exemplo, a Salmed (International Trade Fair of Medical Equipment and Instruments) e a Porto Seguro Investimentos.

\subsection{Beneficiários de planos de saúde e entidades consumeristas}

Os beneficiários dos planos de saúde podem participar das consultas e audiências públicas da ANS tanto individualmente quanto por meio de entidades consumeristas representativas. Elas têm como missão defender direitos e interesses dos usuários ou beneficiários dos setores regulados.

As entidades consumeristas atuantes no setor de saúde suplementar podem ser aquelas de missão ampla, que atuam em defesa de todos os tipos de consumidores, como o Instituto Brasileiro de Defesa do Consumidor ("Idec") e a Associação Brasileira de Defesa do Consumidor. Neste grupo de entidades que atuam com escopo amplo também se incluem entidades estatais, como os Procons dos estados.

Há também aquelas entidades que atuam de forma especializada, em defesa de um grupo específico de beneficiários do setor de saúde suplementar, como grupos de apoio a pacientes reumáticos, portadores de hepatite, customizados, dentre outros.

\subsection{Atores governamentais e suas entidades representativas}

Atores governamentais são organizações estatais não empresariais, pertencentes a órgãos dos três poderes, de órgãos de controle (e.g. tribunais de contas, Controladoria Geral da União) e do Ministério Público.

Nesta categoria também está incluída a própria agência, que também participa dos mecanismos de participação, especialmente quando determinada unidade da 
própria agência não tiver participado do processo de produção da norma ou agenda regulatória colocada para consulta.

Atores governamentais, bem como suas entidades representativas envolvem-se nos mecanismos de participação da ANS quando a regulação proposta interfere de algum modo nas políticas e programas que desenvolvem em suas respectivas pastas.

\subsection{Indivíduos interessados}

Qualquer pessoa, nacional ou estrangeira, residente ou não no país, pode participar dos mecanismos de participação da ANS. Quando estas pessoas não declaram, no momento da inscrição para participação, possuir um interesse específico no setor de saúde suplementar (e.g. consumidor ou profissional da saúde), estas são classificadas apenas como indivíduos interessados.

\subsection{Agentes Públicos}

Agentes públicos são indivíduos que se apresentam como membros de órgãos governamentais, mas que atuam nos mecanismos em nome próprio, sem representar expressamente o referido órgão (e.g. deputado federal, servidor do Ministério da Saúde).

\subsection{Outros atores}

Todas as demais entidades não pertencentes a nenhuma das categorias anteriores, como universidades, empresas de consultoria, organizações religiosas, institutos culturais, dentre outros, são classificadas nesta pesquisa na categoria outros. 


\section{Figura 1}

\section{Grupos de Interesse ou Categorias de Contribuintes}

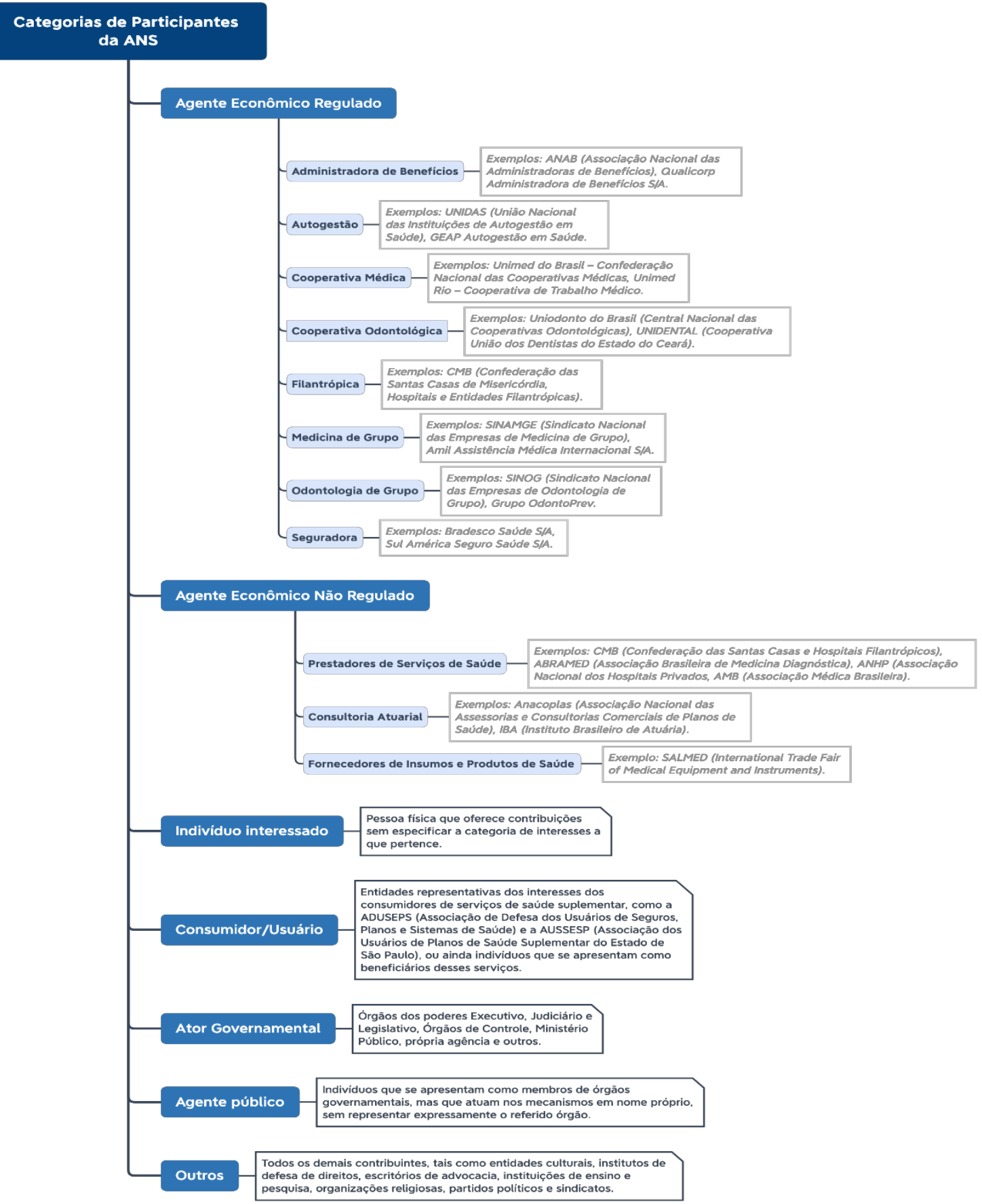




\section{OS GRUPOS DE INTERESSE QUE MAIS PARTICIPAM}

A análise dos grupos de interesse que mais participam enfrenta limitações metodológicas. Como visto, os números apresentados nesta seção e na seguinte não correspondem à totalidade dos dados, mas sim à totalidade dos dados disponibilizados pela ANS. Sobre os grupos que mais participam, não foi possível identificar o número de participantes em 52 mecanismos porque a agência não disponibilizou relatório de análise de contribuições ou, quando o fez, deixou de informar o número total de participantes. ${ }^{19}$

A ANS costuma atrair um número razoável de participantes para suas consultas e audiências públicas. O gráfico 3, a seguir, apresenta a frequência de mecanismos em diferentes faixas de número de participantes. A faixa que concentra a maior frequência de mecanismos é aquela que reúne entre 31 e 50 participantes, seguida da faixa que concentra entre 20 e 30 contribuintes. Estes números contrastam com os de outras agências, em que a faixa com maior frequência é aquela que concentra apenas entre 1 e 5 participantes. ${ }^{20}$

Comparecem, em média, em cada mecanismo de participação, 43,22 contribuintes. ${ }^{21}$ Trata-se da agência reguladora que recebe, após a Anvisa, a segunda maior média de participantes. ${ }^{22} \mathrm{O}$ número médio de participantes varia, no entanto, conforme o objetivo do mecanismo de participação da ANS. A agência realizou consultas e audiências públicas tanto para subsidiar seus processos de produção normativa quanto para instrumentalizar a formulação de sua agenda regulatória. ${ }^{23}$ Para as consultas públicas realizadas com o objetivo de produzir a agenda regulatória, no entanto, a média do número de participantes é menor, de

${ }^{19}$ Em alguns relatórios-síntese produzidos pela agência, é comum constar informações sobre o número de manifestações recebidas, sem, no entanto, informar o número total de participantes.

${ }^{20}$ Este é o caso da Aneel (CPDE, 2020e), Anatel (CPDE, 2020c), Anvisa, Ana (CPDE, 2020a), Ancine (CPDE, 2020d) e ANTT (CPDE, 2020h) e Anac (CPDE, 2020b).

${ }^{21}$ Duas observações merecem ser feitas a respeito deste cálculo da média. Em primeiro lugar, ele exclui outliers, que no presente caso são os mecanismos com número de participantes maior do que 3 desvios padrões acima da média. Por esse método, foi identificado apenas 1 caso classificado como outlier e excluído da análise que se segue - a Consulta Pública n. 61/66, que contou com 238 participantes. Em segundo lugar, como visto, não foi possível identificar o número total de participantes em diversos mecanismos por falta de disponibilidade desta informação. Estão excluídos, do cálculo da referida média, as consultas públicas que tiveram por objetivo atualizar o rol de procedimentos dos planos de saúde, em que a agência informou ter recebido milhares de contribuições, porém não indicou o número total de participantes. Deste modo, pela natureza dos mecanismos em que não foi possível identificar o número total de contribuintes, estima-se que o número médio de participantes da ANS esteja subestimado.

${ }^{22} \mathrm{O}$ número médio de participantes da Anvisa foi de 69,10 pessoas (CPDE, 2020i).

${ }^{23} \mathrm{~A}$ agenda regulatória é um instrumento de planejamento que estabelece, por exemplo, os assuntos que deverão receber especial atenção da agência durante um certo período de tempo. A ANS adotou agenda regulatória para os biênios 2011-2012 e 2013-2014, bem como para os triênios 20162018 e 2019-2021. As três últimas agendas regulatórias adotadas pela agência foram precedidas de consulta pública. 
35,67 contribuintes. Todas as consultas públicas realizadas com este objetivo tiveram número de participantes inferior ao número médio geral, conforme mostra o gráfico 4.

Os mecanismos de participação também atraem números variados de participantes conforme o tema tratado. Consultas e audiências sobre temas relacionados às operadoras de planos de saúde atraem menor público. Isto é compreensível já que estas consultas e audiências públicas tratam de questões de maior interesse dos agentes regulados pela ANS, como normas de acreditação, gestão econômico-financeira e boas práticas de governança corporativa. Já os mecanismos sobre planos de saúde atraem um público mais vasto - incluindo operadoras, beneficiários de planos de saúde e prestadores - o que explica uma adesão acima da média na maioria dos casos, como mostra o gráfico 5. Já as consultas públicas sobre o tema consumidor/usuário também atraem um número relativamente maior de participantes. Os mecanismos de participação que versam sobre planos de saúde e direitos dos beneficiários atraem, portanto, maior público devido à saliência das questões nelas tratadas.

\section{Gráfico 3}

Faixas de Participação (frequência)

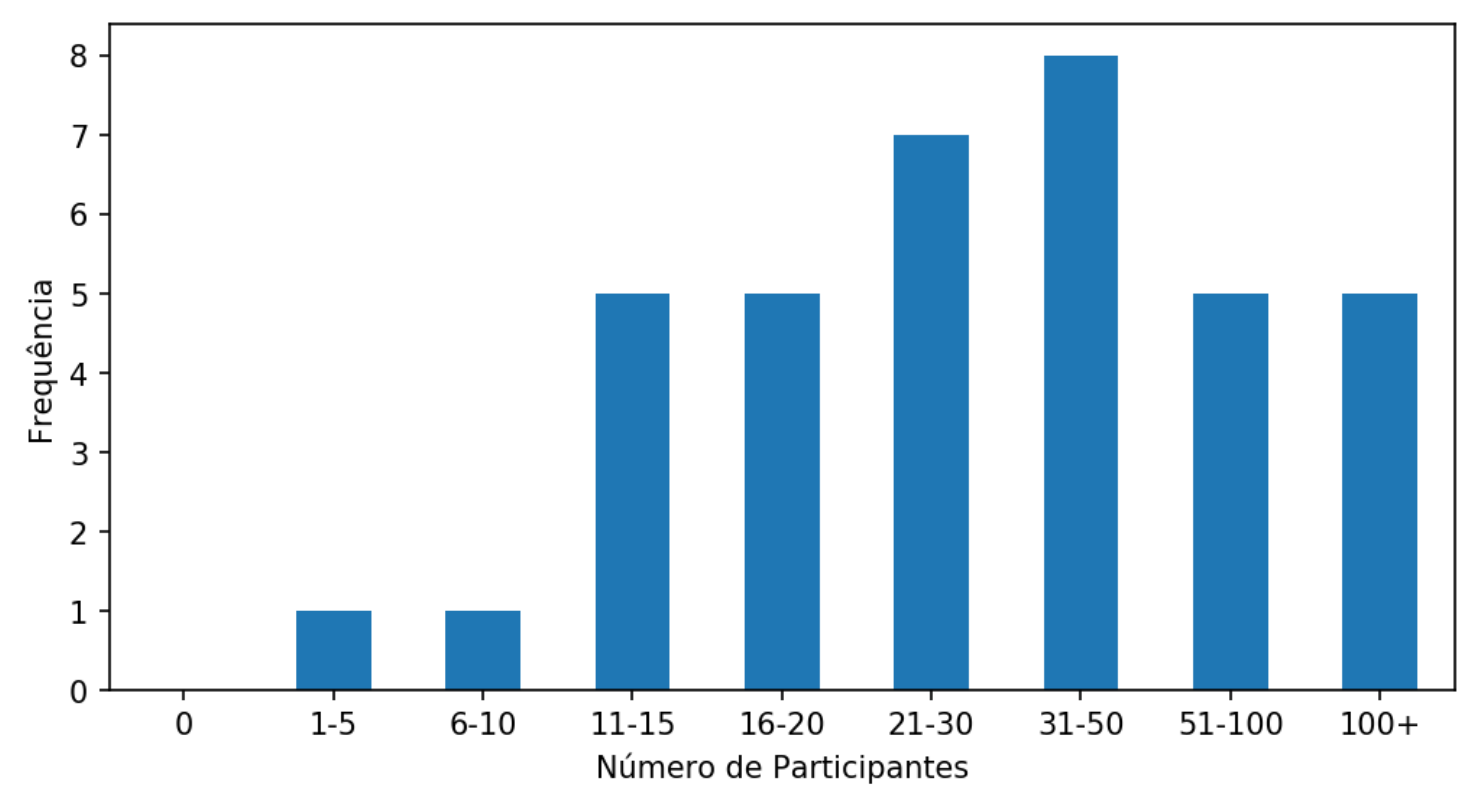

Fonte: elaboração própria a partir de base de dados do Regulação em Números 


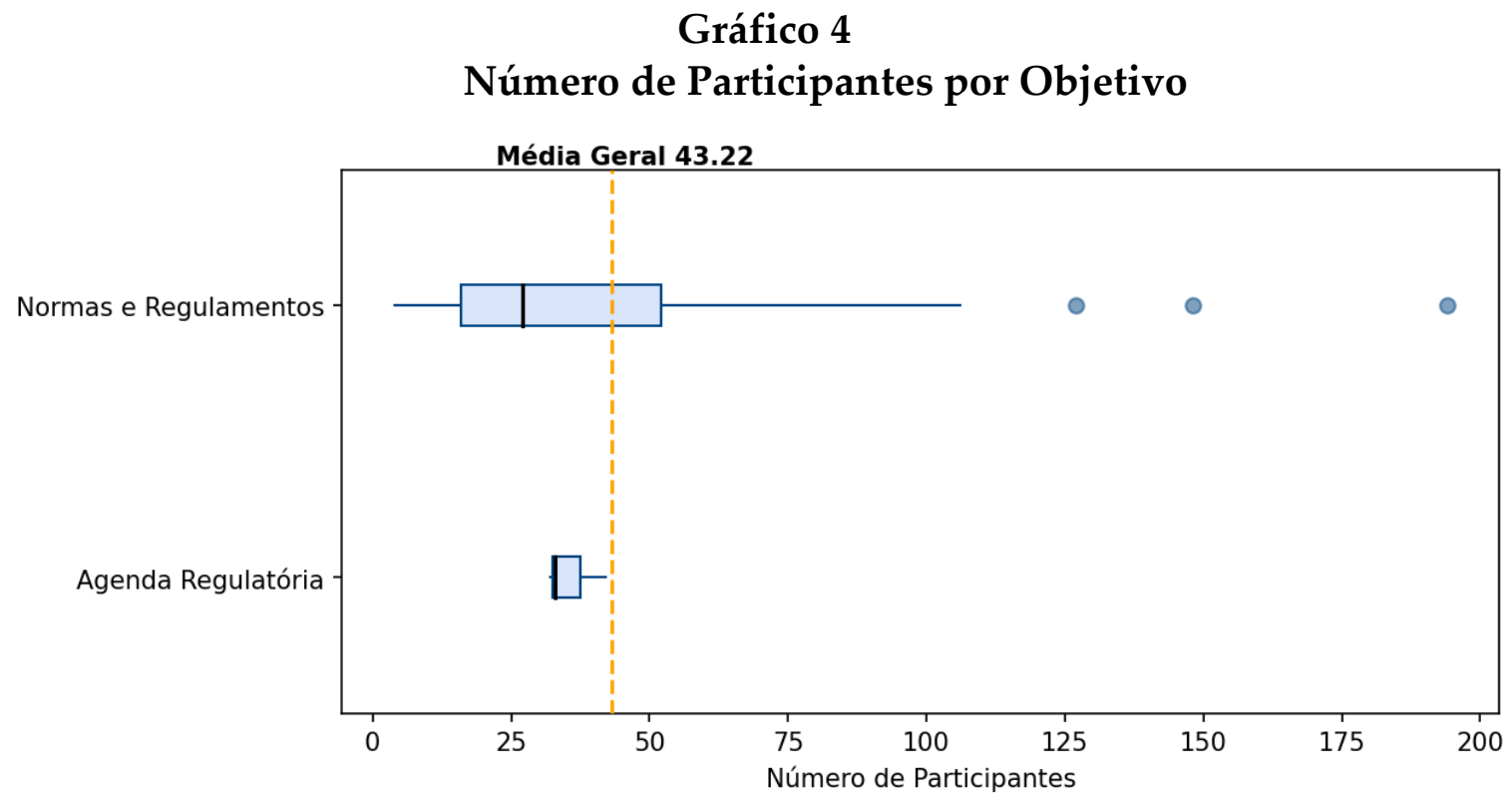

Fonte: elaboração própria a partir de base de dados do Regulação em Números

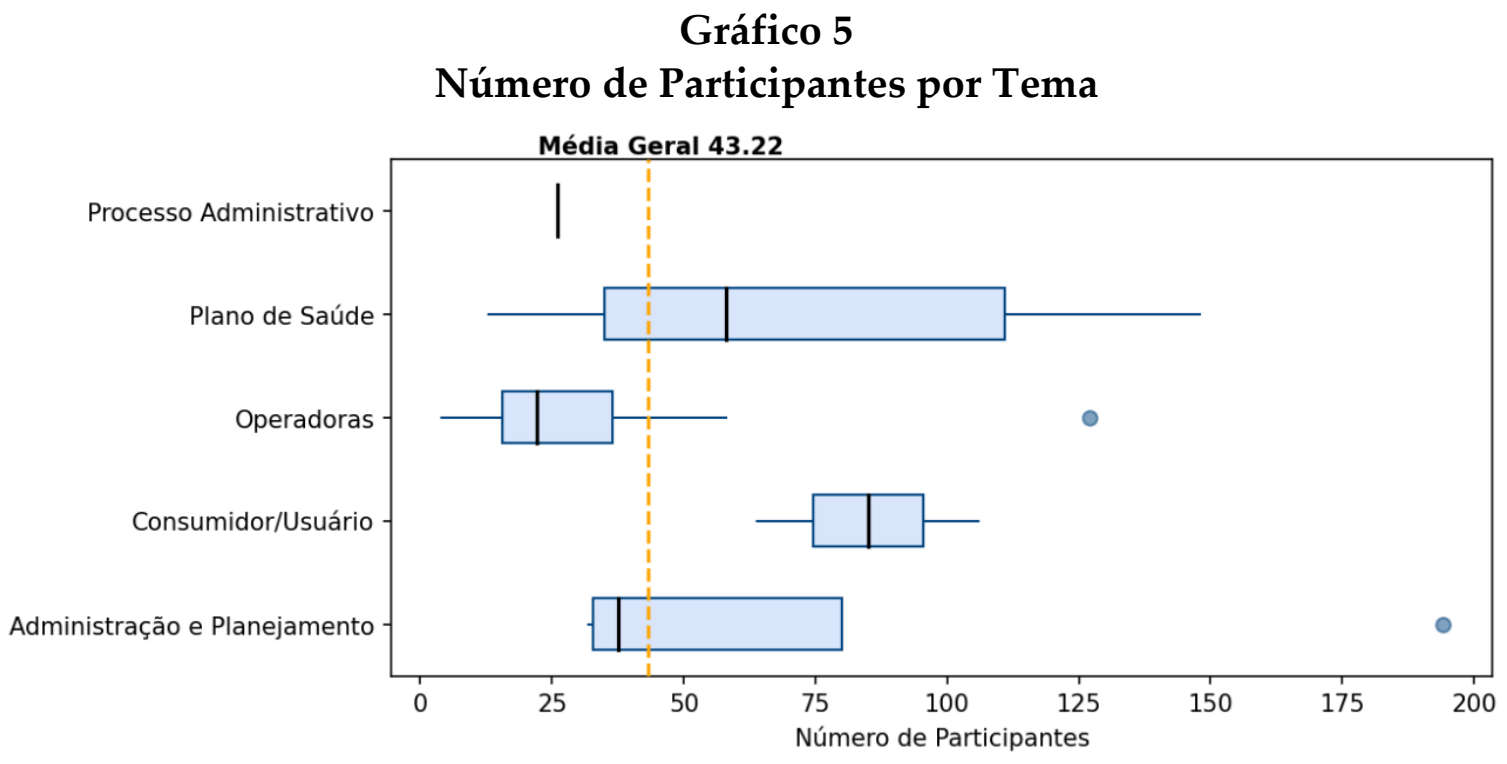

Fonte: elaboração própria a partir de base de dados do Regulação em Números

A distribuição do número de participantes entre as diversas categorias de interesse não é, no entanto, uniforme. As operadoras de planos de saúde, únicos entes regulados pela ANS, são o grupo que mais participa dos mecanismos de participação, conforme mostra o gráfico 6. Cinquenta e quatro vírgula dois por 
cento $(54,2 \%)$ de todas as contribuições identificadas foram provenientes de representantes desta categoria. Este fenômeno, como visto, é observado em outras agências reguladoras, em que agentes econômicos regulados figuram como os principais participantes. ${ }^{24}$

Como visto, há operadoras de diversos segmentos, de modo que foi possível identificar também quais deles mais participam das consultas e audiências públicas da ANS. O gráfico 7 mostra que as cooperativas médicas são o segmento de operadoras que mais participam, seguidas de empresas de autogestão e de medicina de grupo. Como visto, as cooperativas e empresas de medicinas de grupo são, respectivamente, o primeiro e o terceiro segmento de operadoras com maior número de beneficiários. Já as empresas de autogestão são o quarto maior segmento de operadoras do país. As seguradoras, segundo maior segmento em número de beneficiários, é o penúltimo segmento em números de aparições nas consultas e audiências públicas. Isto se explica pelo fato de que o número de seguradoras existente no mercado é menor, havendo uma concentração de mercado para este segmento.

Já os agentes econômicos não regulados são o segundo grupo que mais participa das consultas e audiências públicas da ANS, correspondendo a 18,9\% do total de participantes. Nesta categoria, encontram-se todos os prestadores de serviços de saúde que, como visto, não são diretamente regulados pela ANS, bem como os fornecedores de insumos e produtos de saúde utilizados nos serviços de saúde suplementar.

Já a categoria Consumidor/Usuário é o terceiro grupo que mais participa dos mecanismos de participação da ANS, correspondendo a 7,6\% do total de participantes. Nesta categoria estão incluídos beneficiários individuais de planos de saúde bem como entidades consumeristas das mais diversas.

Participantes das categorias outros, indivíduo interessado e ator governamental representaram, respectivamente, $6,2 \%, 5,1 \%$ e 3,1\% do total de participantes. Por fim, os agentes públicos representam $0,5 \%$ dos contribuintes dos mecanismos de participação da ANS.

\footnotetext{
${ }^{24}$ Isto ocorre também nos mecanismos de participação realizados pela Aneel (CPDE, 2020e), Ana (CPDE, 2020a), Ancine, (CPDE, 2020d), CVM (CPDE, 20201) e Antaq (CPDE, 2020g).
} 


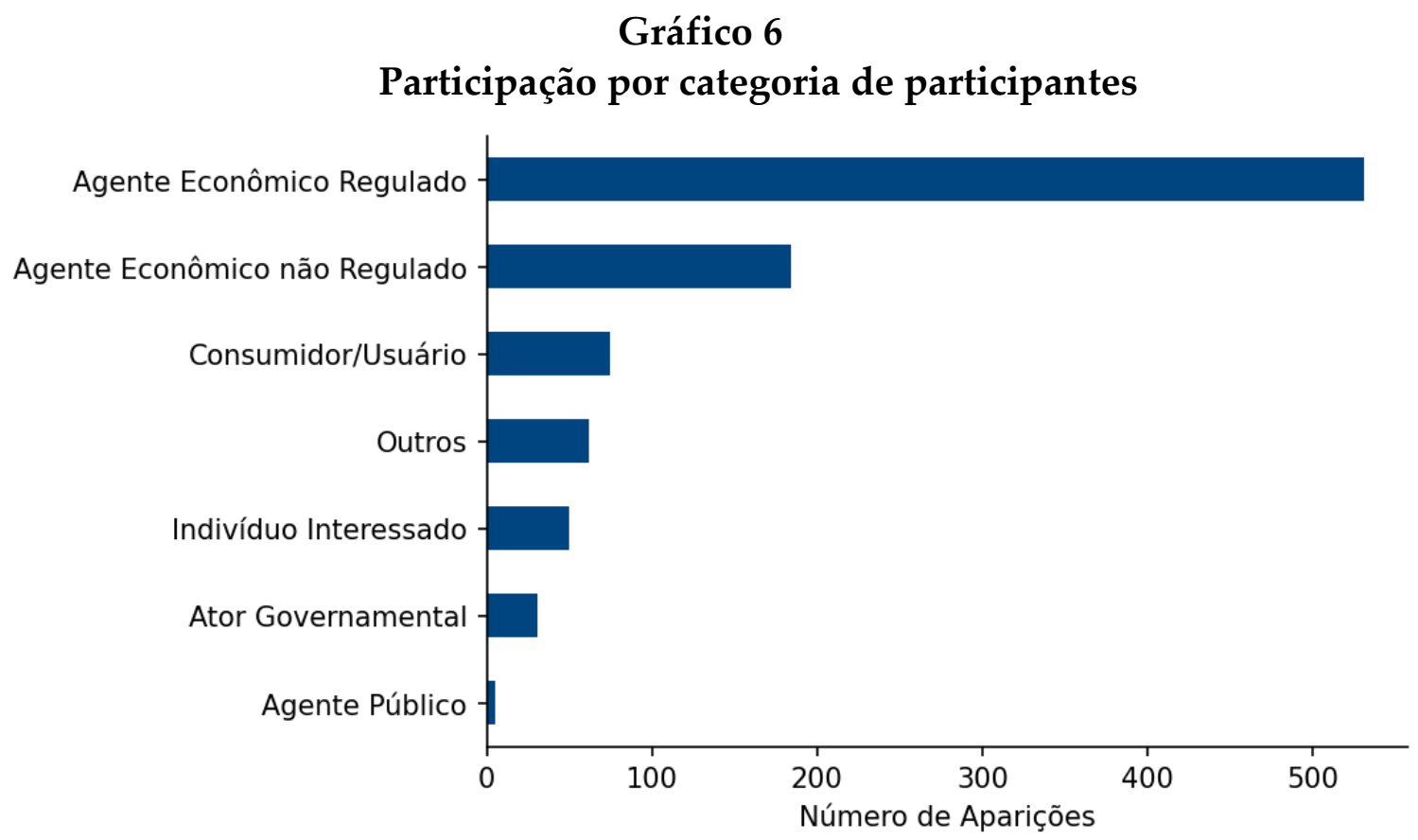

Fonte: elaboração própria a partir de base de dados do Regulação em Números

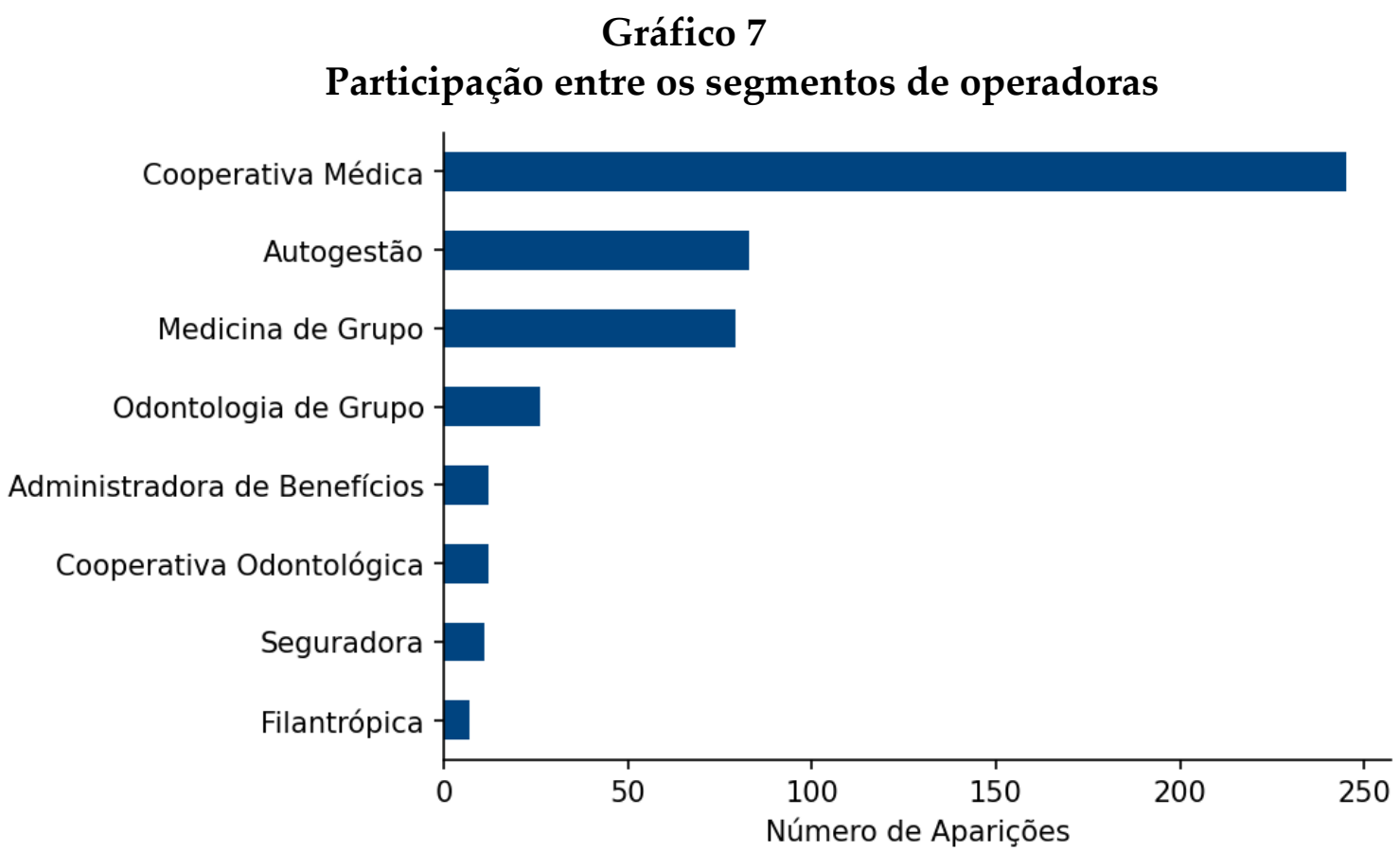

Fonte: elaboração própria a partir de base de dados do Regulação em Números 
Em média, cada participante das consultas e audiências públicas da ANS costuma apresentar 6,24 manifestações por mecanismo de participação. O gráfico 8 , no formato boxplot ${ }^{25}$, mostra as distribuições das manifestações por contribuinte em cada mecanismo de participação. Agentes econômicos regulados e consumidores apresentam contribuições individuais em número superior ao da média geral.

Dentre os diversos segmentos de operadoras, as cooperativas, empresas de autogestão e as empresas de medicina e odontologia de grupo são aquelas que também apresentam um número maior de contribuições individuais, como mostra o gráfico 9 .

\section{Gráfico 8}

Número de manifestações por categoria de contribuinte

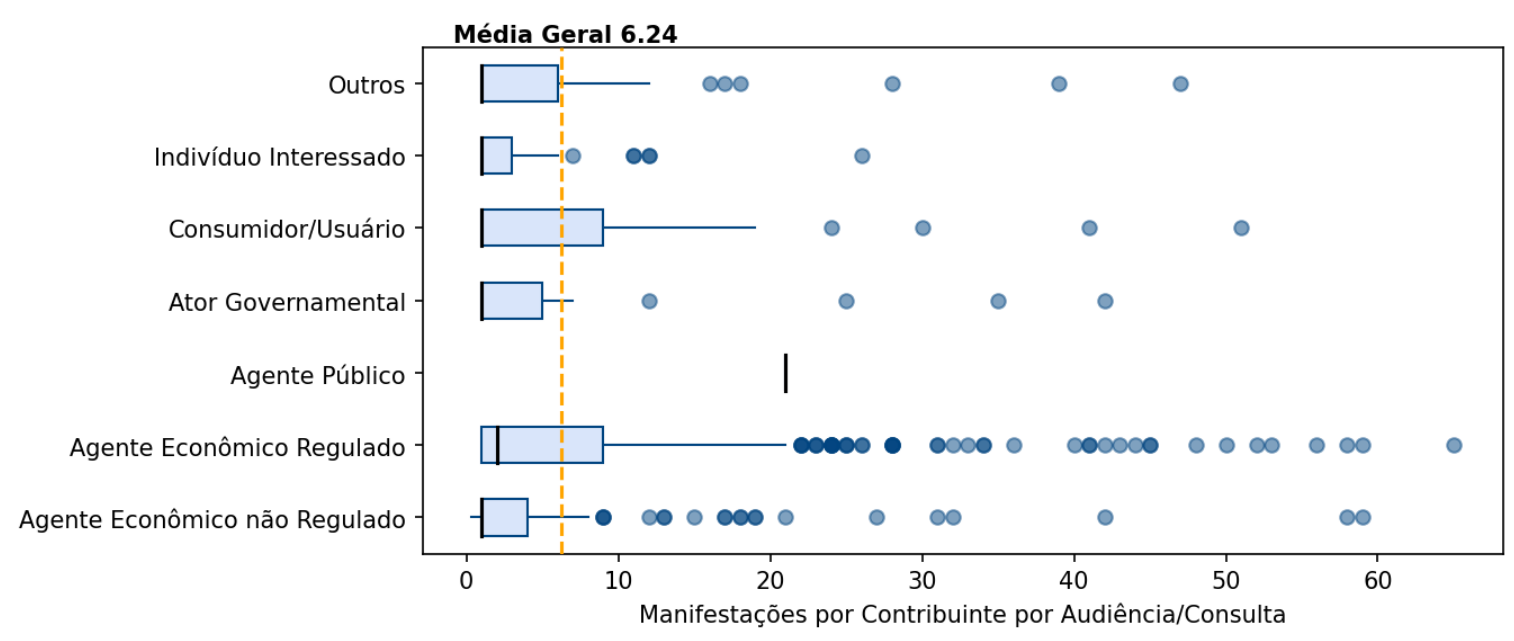

Fonte: elaboração própria a partir de base de dados do Regulação em Números

\footnotetext{
${ }^{25}$ Nos gráficos apresentados no formato Boxplot, a mediana é identificada por linhas pretas escuras no interior de cada caixa. Os intervalos compreendidos pelas caixas azuis representam a amplitude entre o primeiro e o terceiro quartil, correspondente a $50 \%$ dos dados intermediários. Os traços azuis representam os casos fora deste intervalo. Os pontos para além das linhas representam potenciais outliers, calculados pelo método tradicional (pontos a uma distância de mais de $1.5^{*} \mathrm{IQR}$ de Q1 ou de Q3).
} 


\section{Gráfico 9 \\ Número de manifestações por segmento de operadora}

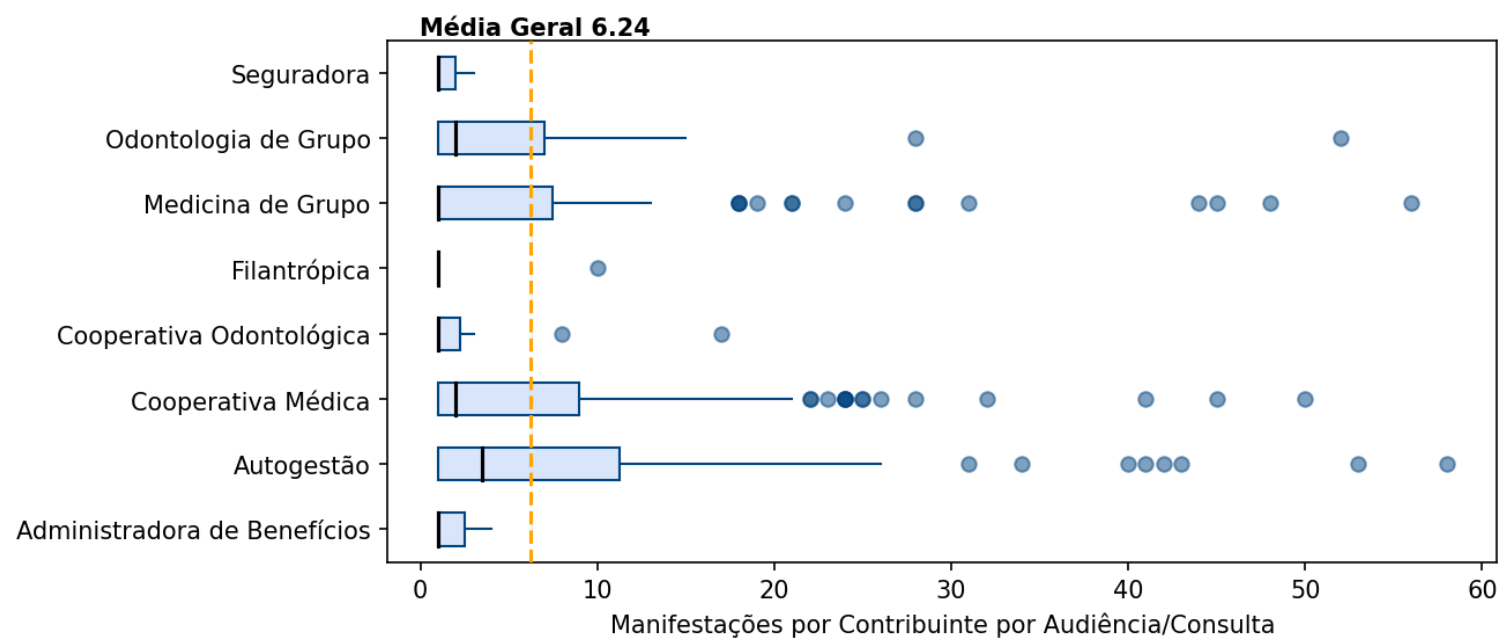

Fonte: elaboração própria a partir de base de dados do Regulação em Números

Quinhentas e noventa e duas pessoas diferentes foram identificadas como participantes dos mecanismos de participação da ANS ${ }^{26}$. Deste número, 113 (19\% do total de contribuintes) participaram de 2 ou mais mecanismos realizados pela ANS. A Tabela 1 indica os dez maiores participantes dos mecanismos analisados. Desses dez, seis - a Fenasaúde, Abramge, Unimed do Brasil, Sinog, Unidas e Unimed do Estado do Paraná - são entidades representativas das operadoras de planos de saúde. A Fenasaúde ${ }^{27}$, entidade representativa de 15 grupos de operadoras de planos de saúde e odontológicos, participou de 23 mecanismos de participação. A Abramge principais entidades representativas do segmento de operadoras de medicina de grupo, participou 22 vezes. Embora os dados analisados não correspondam ao universo dos mecanismos de participação, pelos motivos já explicitados, percebe-se que os participantes mais assíduos são aqueles que representam os interesses dos agentes econômicos e dos beneficiários dos planos de saúde.

Um fato curioso é o de que a ANS figura como o sexto participante mais assíduo. Trata-se da participação de membros da própria agência - geralmente de uma superintendência distinta da que lançou o mecanismo - que se utilizam do mecanismo de participação para apresentar suas experiências com o objeto

${ }^{26}$ Como visto, não foi possível identificar o número de participantes de mais da metade dos mecanismos de participação, razão pela qual este número deve ser visto como apenas correspondente aos casos analisados.

27 Até 2007, a Federação Nacional das Empresas de Seguros Privados e de Capitalização (Fenaseg) foi a principal entidade representativa deste segmento. Esta entidade desmembrou-se em várias entidades representativas de seguros, sendo que a representação da área de saúde suplementar passou a ser exercida pela Federação Nacional de Saúde Suplementar (Fenasaúde). 
discutido, ou com temas correlacionados, e oferecer sugestões acerca das soluções mais apropriadas.

\section{Tabela 1 - Entidades que mais participaram}

\begin{tabular}{lc}
\multicolumn{1}{c}{ Entidades } & $\begin{array}{c}\text { Número de } \\
\text { mecanismos }\end{array}$ \\
\hline Fenasaúde (Federação Nacional de Saúde Suplementar) & 23 \\
Abramge (Associação Brasileira de Medicina de Grupo) & 22 \\
Unimed do Brasil (Confederação Nacional das Cooperativas Médicas) & 21 \\
Sinog (Sindicato Nacional das Empresas de Odontologia de Grupo) & 16 \\
Unidas (União Nacional das Instituições de Autogestão em Saúde) & 14 \\
ANS (Agência Nacional de Saúde Suplementar) & 14 \\
Unimed Belo Horizonte Cooperativa de Trabalho Médico Ltda & 10 \\
Unimed do Estado do Paraná - Federação Estadual de Cooperativas Médicas & 9 \\
Unimed Curitiba - Sociedade de Cooperativas Médicas & 9 \\
Unimed Vitória - Cooperativa de Trabalho Médico & 8
\end{tabular}

A identificação dos grupos de interesse que participam dos processos decisórios da ANS não informa, no entanto, sobre a influência desta participação nas decisões finais da agência. Para isto, é necessário que se verifique também se a agência acata ou não as sugestões destes grupos. Isto é tratado no próximo item.

\section{A INFLUÊNCIA DOS GRUPOS DE INTERESSE NO PROCESSO REGULATÓRIO DA ANS}

Como visto, a análise da participação dos grupos de interesse e de sua influência nos processos decisórios da ANS sofre limitações devido à indisponibilidade ou falta de clareza de parte significativa dos dados. O gráfico 10 mostra que não é possível identificar a resposta de $72,2 \%$ das contribuições mencionadas nos relatórios. Entre as respostas completas, 16,3\% aceitaram as contribuições dos participantes e $10,4 \%$ as rejeitaram. Além disso, 0,2\% das respostas individualizadas não eram claras $^{28}$ e $0,9 \%$ das contribuições foram consideradas não aplicáveis ${ }^{29}$. Ao retirar-se as contribuições sem resposta do universo analisado, verifica-se, no gráfico 11, que 58,7\% das manifestações foram aceitas, 37,5\% foram rejeitadas, 3,2\% não receberam resposta clara e $0,6 \%$ foram consideradas não aplicáveis.

\footnotetext{
${ }^{28}$ Respostas não claras são aquelas em que não é possível identificar com clareza se a agência acatou ou rejeitou a contribuição recebida. Tratam-se de respostas evasivas que exigem interpretação subjetiva para serem decifradas. Neste trabalho, optou-se por classificar estas respostas como não claras.

${ }^{29}$ A agência classifica como "não aplicáveis" contribuições de teor repetido propostas pelo mesmo autor, bem como manifestações que fogem do escopo da consulta ou audiência pública.
} 


\section{Gráfico 10 \\ Impacto das Contribuições (percentuais)}

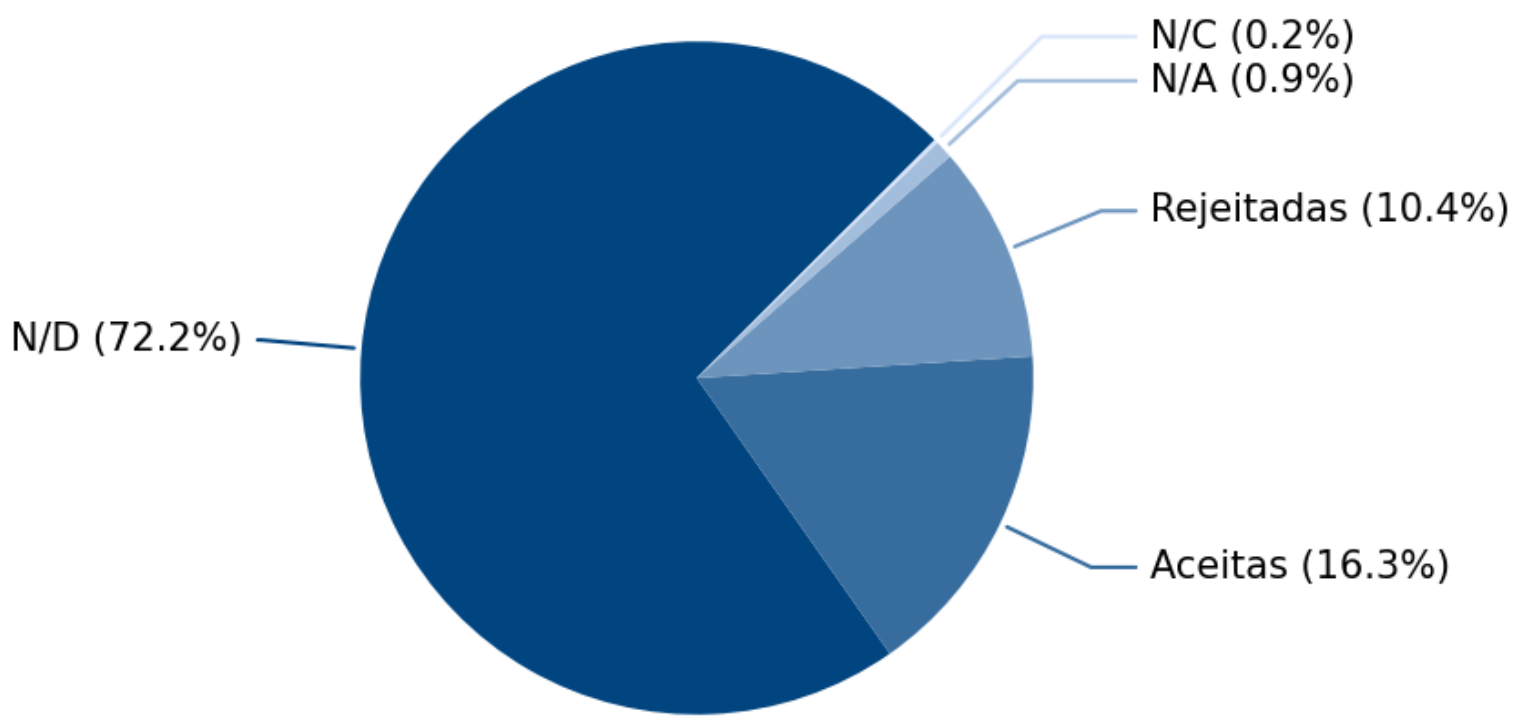

\section{Gráfico 11}

Impacto relativo das contribuições (percentuais)

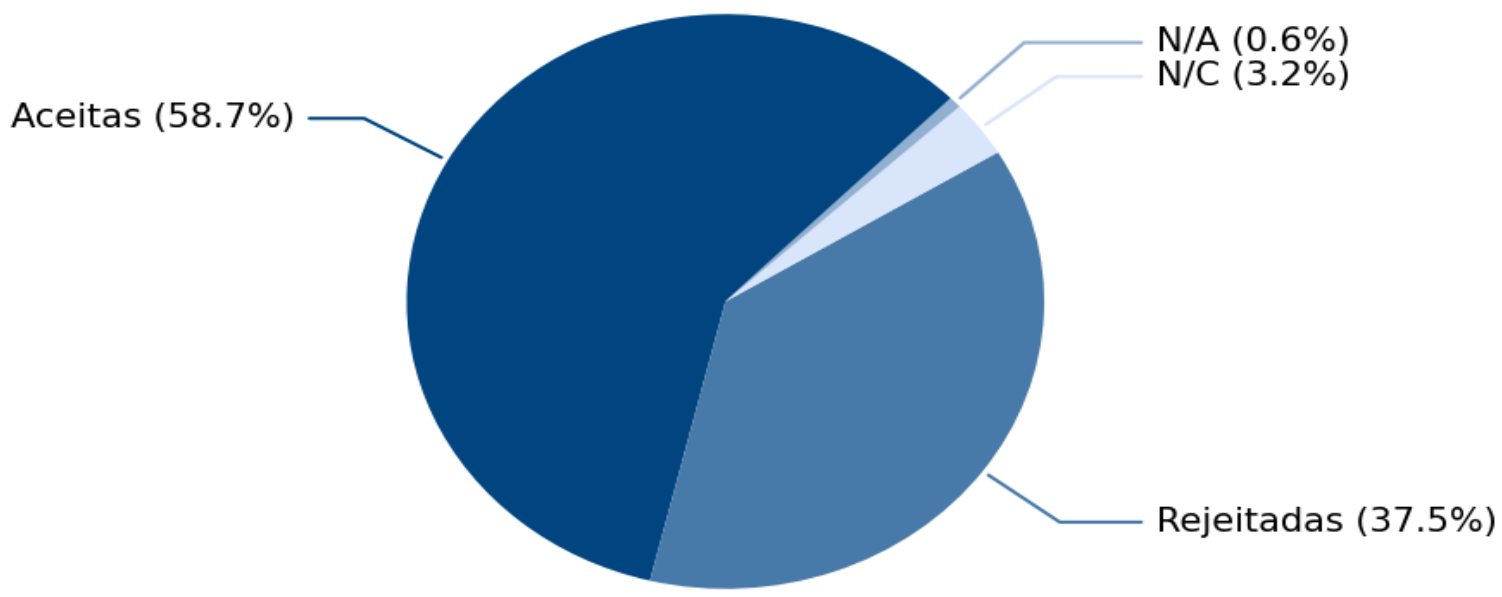


Embora a agência acate a maioria das contribuições que recebe, cabe analisar ainda se este padrão de resposta é uniforme entre os diferentes grupos de interesse.

O gráfico 12 mostra, em números absolutos e percentuais, o conjunto de contribuições aceitas, rejeitadas, não claras e não aplicáveis para cada grupo de interesse. Como para parcela significativa das contribuições a agência não ofereceu uma resposta individualizada, cabe analisar o seu índice de aceitação e rejeição em termos relativos, ou seja, sem considerar as respostas não disponíveis. Os agentes econômicos regulados tiveram, nesses termos, 47,4\% de aceitação, 47,6\% de rejeição, 3,4\% de respostas não claras e 1,4\% de contribuições consideradas não aplicáveis. Embora a agência aceita mais do que rejeita as contribuições dos regulados, não é possível afirmar que este goza de favoritismo em relação a outros grupos de interesse. O gráfico 13 mostra, por sua vez, o impacto relativo das contribuições de cada segmento de operadora. De todos os segmentos, as cooperativas são a única modalidade de operadoras com índice de rejeição maior do que o índice de aceitação.

Já para a categoria "agente econômico não regulado", que na ANS são representados pelos prestadores de serviços de saúde e os fornecedores de insumos e produtos de saúde, a predisposição de aceitação das contribuições é maior: 51,9\% de aceitação, contra 39,9\% de rejeição, 4,3\% de respostas não claras e 3,7\% de contribuições não aplicáveis.

Para a categoria "consumidor/usuário", terceiro grupo de interesse mais participativo, o índice relativo de aceitação das contribuições deste grupo é de $47,6 \%$, contra $35,9 \%$ de rejeição, $0,4 \%$ de respostas não claras e $15,8 \%$ de contribuições não aplicáveis. Novamente, deve-se frisar que estes índices são relativos, referindo-se apenas às contribuições deste grupo em que foi possível identificar a resposta da agência. De todo modo, para os casos em que houve resposta, a proporção entre o percentual de aceitação e o de rejeição é idêntica à da categoria dos agentes econômicos não regulados.

Os participantes classificados na categoria "ator governamental" possuem índice de aceitação relativo ainda mais alto - 63,2\% contra $31,6 \%$ de rejeição. Para cada contribuição de atores governamentais rejeitadas, duas são aceitas. Atores governamentais, como visto, são organizações estatais não empresariais, pertencentes a órgãos dos três poderes, de órgãos de controle (e.g. tribunais de contas, Controladoria Geral da União) e do Ministério Público. Aqui cabe a ressalva de que o número bruto de contribuições deste grupo de interesse é consideravelmente menor do que o número de bruto de manifestações de outras categorias, como agentes econômicos regulados. De todo modo, o fato de que atores governamentais gozam de alto índice de aceitação é um fenômeno observado em outras agências reguladoras, como Anac (CPDE, 2020b), Anvisa (CPDE, 2020i) e Aneel (CPDE, 2020e).

Já os participantes classificados na categoria "indivíduos interessados" possuem índice relativo de aceitação de apenas 31,5\%, contra 59,3\% de rejeição, 3\% de respostas não claras e $6 \%$ de contribuições não aplicáveis. Indivíduos 
interessados são pessoas físicas que não representam ou não declaram representar nenhum grupo de interesse específico. É possível, no entanto, que beneficiários individuais de planos de saúde também façam parte desta categoria, especialmente quando não se autodeclaram consumidores no momento do envio da contribuição à consulta ou audiência pública da ANS. De qualquer modo indivíduos interessados não agem de forma coordenada, o que talvez explique o alto índice de rejeição de suas contribuições.

Gráfico 12

Impacto das contribuições por categoria de participante
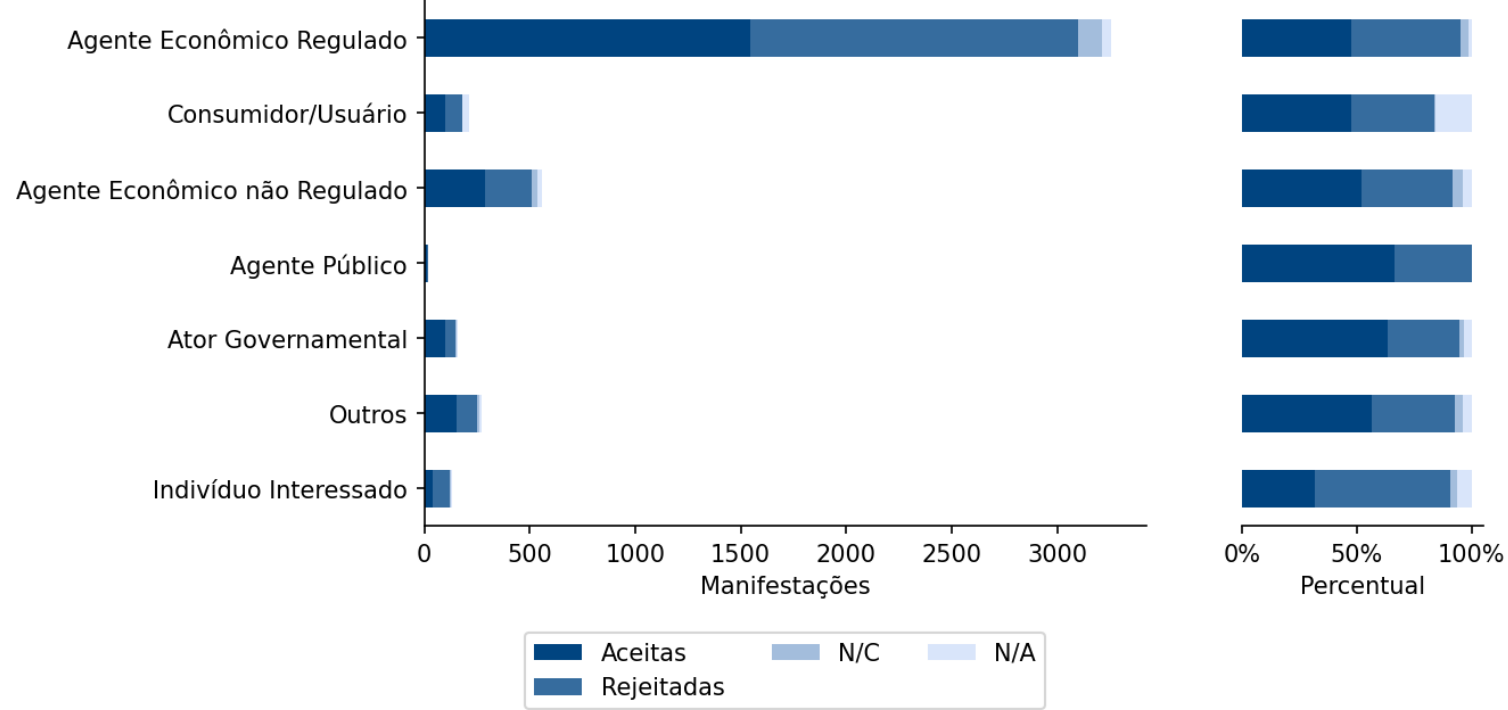

Gráfico 13

Impacto das contribuições por segmento de operadoras
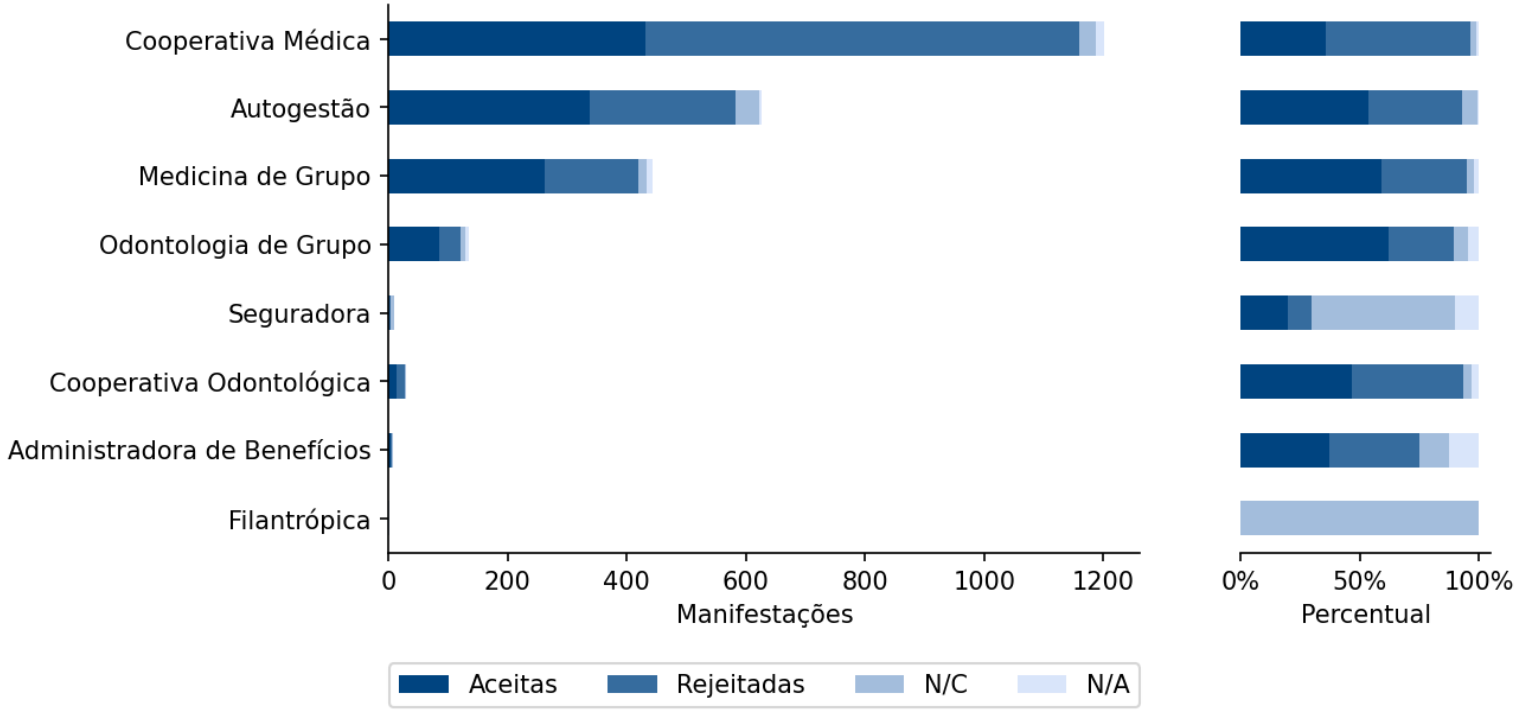

Rejeitadas $\mathrm{N} / \mathrm{C}$ 
Como visto, seis dos dez maiores participantes das consultas e audiências públicas da ANS são entidades representativas dos agentes econômicos regulados. As entidades representativas buscam, nesse sentido, coordenar as ações de grupos coletivos de operadoras, dos prestadores de serviços de saúde e dos beneficiários dos planos de saúde. Como visto, está na própria definição de grupo de interesse a ideia de ação coletiva coordenada. Resta saber, deste modo, se a atuação das entidades representativas é efetiva nos mecanismos de participação da ANS.

As entidades representativas são as proponentes de $20,2 \%$ das contribuições de todas as categorias de participantes das audiências e consultas públicas da ANS e de 20,9\% de todas as contribuições dos agentes econômicos regulados (CPDE, 2020f).

O gráfico 14 mostra o impacto das manifestações dos participantes individuais e representativos dos mecanismos da ANS. As contribuições da totalidade de participantes individuais tiveram $48 \%$ de aceitação, $46,6 \%$ de rejeição, $3 \%$ de respostas não claras e 2,2\% de contribuições não aplicáveis. Já as contribuições das entidades representativas de todas as categorias de participantes tiveram $49,8 \%$ de aceitação, $42,8 \%$ de rejeição, 3,8\% de respostas não claras e 3,5\% de contribuições não aplicáveis.

Analisando apenas as contribuições individuais dos agentes econômicos regulados, verifica-se um índice de 44,9\% de aceitação, 50,4\% de rejeição, 3,5\% de respostas não claras alisando e $1 \%$ de contribuições não aplicáveis. Já as contribuições das entidades representativas dos regulados tiveram $50,8 \%$ de aceitação, $43,8 \%$ de rejeição, 3,3\% de respostas não claras e 1,9\% de contribuições não aplicáveis.

Em suma, as entidades representativas de todos os grupos de interesse, e em especial dos regulados, apresentam índices de aceitação de suas contribuições maiores do que os dos participantes individuais, conforme se verifica nos gráficos 14 e 15 . 


\section{Gráfico 14}

Impacto das contribuições das entidades representativas
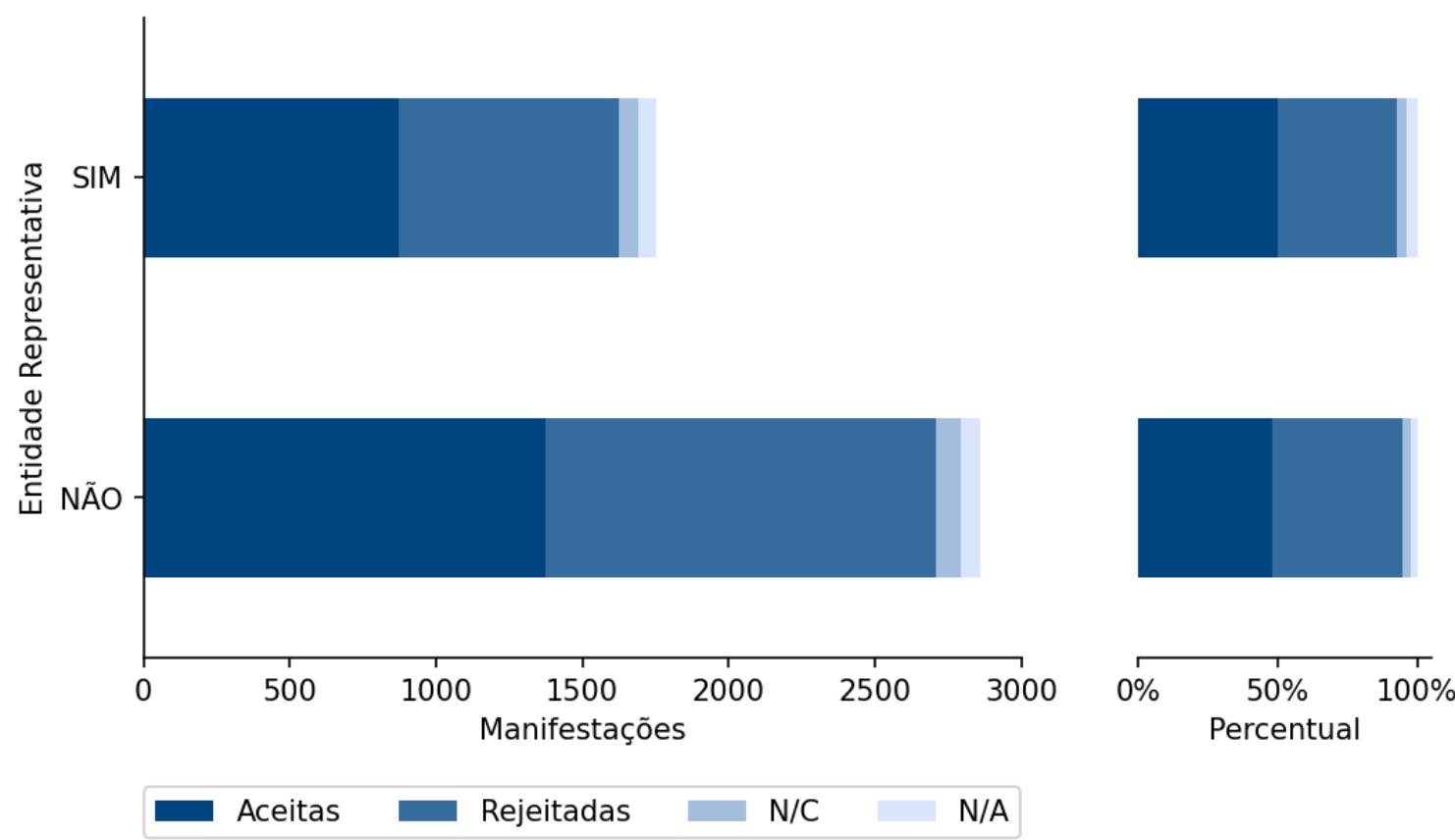

$\mathrm{N} / \mathrm{C}$

N/A

Gráfico 15

Impacto das contribuições das entidades representativas das operadoras
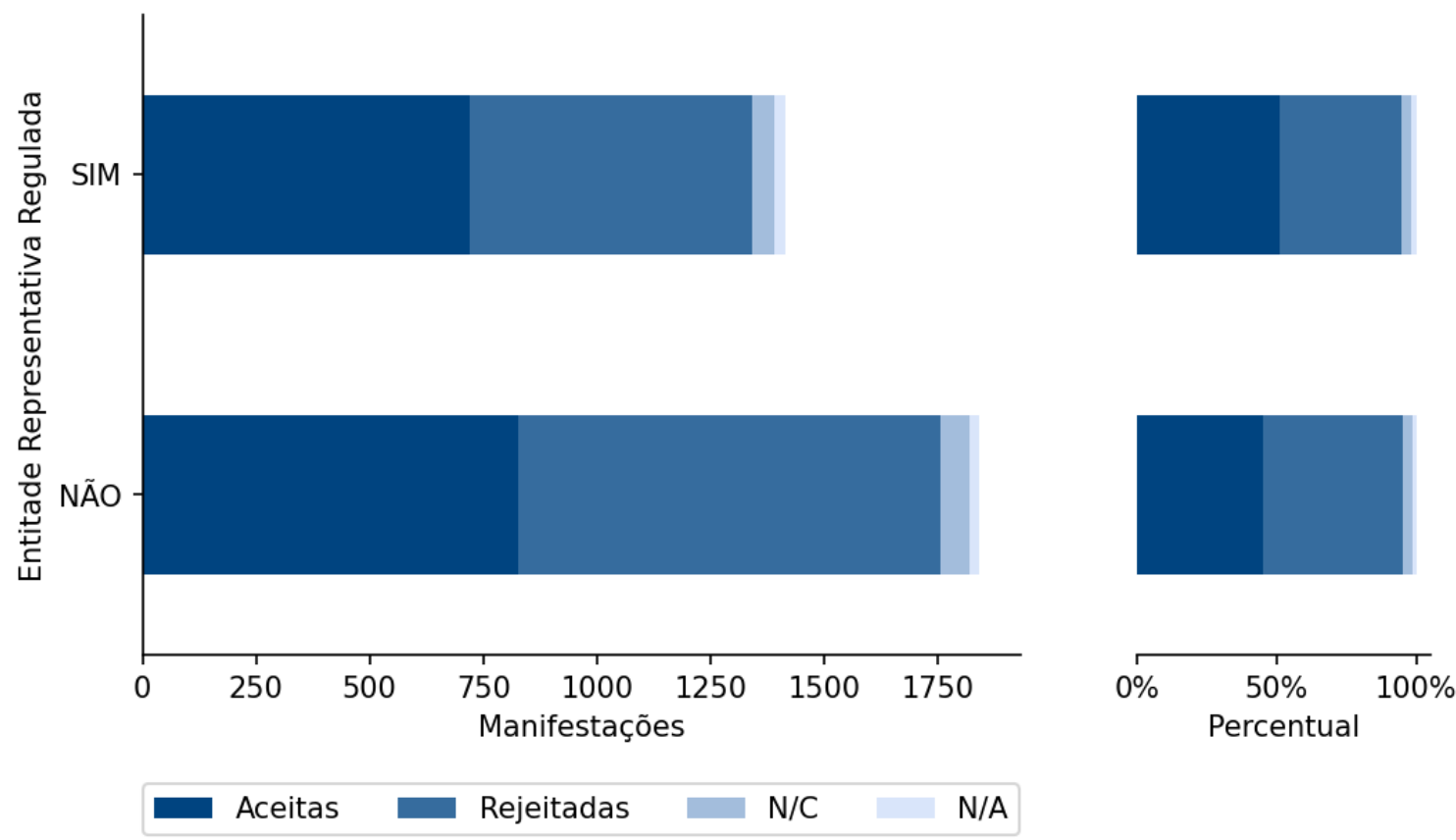


\section{CONCLUSÃO}

Algumas conclusões podem ser extraídas da análise empírica das consultas e audiências públicas da ANS. Os mecanismos de participação são, sem dúvida, espaços hoje ocupados pelos grupos de interesse para influenciar a tomada de decisão regulatória na ANS.

A ANS figura entre as agências com maior número de participantes em suas consultas e audiências públicas. Como visto, o número médio de participantes nas consultas e audiências públicas da ANS é superior ao da maioria das agências reguladoras federais.

Em parte, esta alta adesão de participantes se explica pela saliência dos temas tratados nas consultas e audiências públicas, que afetam interesses de diferentes grupos simultaneamente.

As operadoras de planos de saúde, únicos entes regulados pela ANS, são o grupo que mais participa dos mecanismos de participação, fenômeno já observado pela literatura empírica nacional e estrangeira.

A ANS aprova mais do que rejeita as contribuições que recebe dos agentes regulados nas audiências e consultas públicas. No entanto, assim como em estudo anterior (Silva, 2012) não foi possível observar um favoritismo do setor regulado para influenciar o processo regulatório. $O$ percentual de aprovação das contribuições dos regulados é inclusive inferior ao percentual de aprovação das manifestações de outras categorias de participantes - como a dos prestadores, beneficiários de planos de saúde e atores governamentais.

De todas as categorias de participantes, atores governamentais são aqueles que têm maior percentual de contribuições aceitas. Este fenômeno não é isolado para a ANS, ocorrendo também em outras agências reguladoras.

Seis das dez entidades que mais participam das consultas e audiências públicas da ANS são entidades representativas do setor regulado. As entidades representativas, não só do setor regulado, mas de todas as demais categorias de participantes, recebem respostas mais favoráveis da ANS do que os participantes individuais. Como visto, está na própria definição de grupo de interesse a ideia de ação coletiva coordenada, a qual parece ser bem exercida pelas entidades representativas do setor suplementar.

\section{REFERÊNCIAS}

BAGLEY, Nicolas. Agency Hygiene. Texas Law Review, vol. 89, 2010, p. 1-14.

BAIRD, Marcello Fragano. Redes de influência, burocracia, política e negócios na Agência Nacional de Saúde Suplementar. Universidade de São Paulo (Doutorado em Ciência Política), 2017, p. 103. 
BAIRD, Marcelo Fragano; FERNANDES, Ivan Filipe de Almeida Lopes. Flying in Clear Skies: Technical Arguments Influencing ANAC Regulations. Brazilian Political Science Review, vol. 8, n. 4, 2014, p. 70-92.

BRASIL (2000a). Agência Nacional de Saúde Suplementar. Resolução de Diretoria Colegiada - RDC da ANS n. 39, 27 de outubro de 2000. Dispõe sobre a definição, a segmentação e a classificação das Operadoras de Planos de Assistência à Saúde.

Disponível em: <

http://www.ans.gov.br/component/legislacao/?view=legislacao\&task=TextoLei\&fo rmat=raw\&id=Mzgw\#: :text=RESOLU\%C3\%87\%C3\%83O\%20DE\%20DIRETORIA $\% 20$ COLEGIADA \%20\%E2\%80\%93\%20RDC,Planos\%20de\%20Assist $\%$ C3\%AAncia $\% 20 \%$ C3\%A0\%20Sa\%C3\%BAde>. Acesso em 5 out. 2020.

BRASIL. Agência Nacional de Saúde Suplementar. Resolução Normativa n. 137, de 14 de novembro de 2006. Dispõe sobre as entidades de autogestão no âmbito do sistema de saúde suplementar. Disponível em: <

http://www.ans.gov.br/component/legislacao/?view=legislacao\&task=TextoLei\&fo rmat=raw\&id=MTExNw==>. Acesso em 5 out. 2020.

BRASIL. Agência Nacional de Saúde Suplementar. A Resolução da ANS n. 196, de 14 de julho de 2009. Dispõe sobre a Administradora de Benefícios. Disponível em: $<$

http://www.ans.gov.br/component/legislacao/?view=legislacao\&task=TextoLei\&fo rmat=raw\&id=MTQ1OQ==\#: :text=RESOLU\%C3\%87\%C3\%830\%20NORMATIVA \%20\%2D\%20RN\%20N\%C2\%BA\%20196,sobre\%20a\%20Administradora\%20de\%20 Benef\%C3\%ADcios.\&text=I\%20\%E2\%80\%93\%20promover\%20a\%20reuni\%C3\%A3 o\%20de,14\%20de\%20julho\%20de\%202009>. Acesso em: 5 out. 2020.

BRASIL. Lei n. 5.764, de 16 de dezembro de 1971. Define a Política Nacional de Cooperativismo, institui o regime jurídico das sociedades cooperativas, e dá outras providências. Disponível em: <

http://www.planalto.gov.br/ccivil_03/leis/15764.htm\#: :text=LEI\%20N\%C2\%BA\%2 05.764\%2C\%20DE\%2016,cooperativas\%2C\%20e\%20d\%C3\%A1\%20outras\%20provi d\%C3\%AAncias.>. Acesso em: 5 out. 2000.

BRASIL. Lei n. 9.656, de 3 de junho de 1998. Dispõe sobre os planos e seguros privados de assistência à saúde. Disponível em: < http://www.planalto.gov.br/ccivil_03/leis/L9656compilado.htm>. Acesso em: 5 out. 2020 . 
BRASIL. Lei n. 9.784, de 29 de janeiro de 1999. Regula o processo administrativo no âmbito da Administração Pública Federal. Disponível em:

http://www.planalto.gov.br/ccivil_03/leis/19784.htm. Acesso em: 5 out. 2020.

BRASIL (2000b). Lei n. 9.961, de 28 de janeiro de 2000. Cria a Agência Nacional de Saúde Suplementar - ANS e dá outras providências. Disponível em: <

http://www.planalto.gov.br/ccivil_03/leis/19961.htm>. Acesso em 5 out. 2020.

BERNSTEIN, Marver. Regulating Business by Independent Commission. Princeton: Princeton University Press, 1955.

Centro de Pesquisas em Direito e Economia - CPDE (2020a). Mecanismos de Participação da Agência Nacional de Águas (ANA). Rio de Janeiro, 2020.

(2020b) Mecanismos de Participação da Agência Nacional de Aviação

Civil (Anac). Rio de Janeiro, 2020 b.

(2020c) Mecanismos de Participação da Agência Nacional de

Telecomunicações (Anatel). Rio de Janeiro, 2020.

. (2020d) Mecanismos de Participação da Agência Nacional de Cinema (Ancine). Rio de Janeiro, 2020.

(2020e) Mecanismos de Participação da Agência Nacional de Energia

Elétrica (Aneel). Rio de Janeiro, 2020.

. (2020f) Mecanismos de Participação da Agência Nacional de Saúde

Suplementar (ANS). Rio de Janeiro, 2020.

(2020g) Mecanismos de Participação da Agência Nacional de Transporte Aquaviário (Antaq). Rio de Janeiro, 2020.

(2020h) Mecanismos de Participação da Agência Nacional de Transporte

Terrestre (ANTT). Rio de Janeiro, 2020.

. (2020i) Mecanismos de Participação da Agência Nacional de Vigilância

Sanitária (Anvisa). Rio de Janeiro, 2020.

(2020j) Mecanismos de Participação do Banco Central (Bacen). Rio de

Janeiro, 2020. 


\section{(20201) Mecanismos de Participação da Comissão de Valores Mobiliários}

(CVM). Rio de Janeiro, 2020.

CHEIT, Ross. Setting Safety Standards: Regulation in the Private and Public Sectors. Berkeley: University of California Press, 1990.

GOLDEN, Marissa Martino. Interest Groups in the Rule-Making Process: who participates? Whose voices get heard? Journal of Public Administration Research and Theory, vol. 8, n. 2, 1998, p. 245-270.

KERWIN, Cornelius; FURLONG, Scott R.; WEST, William. Interest Groups, Rulemaking, and American Bureaucracy. In: The Oxford Handbook of American Bureaucracy. Robert F. Durant, 2011. Disponível em: < https://www.oxfordhandbooks.com/view/10.1093/oxfordhb/9780199238958.001.00 01/oxfordhb-9780199238958-e-25>. Acesso em 5 out. 2020.

FRITSCHLER, A. Lee. Smoking and Politics. 4. Ed. Englewood Cliff, NJ: Prentice Hall, 1989.

FURLONG, Scott R.; KERWIN, Cornelius. Interest Group in Rulemaking: a decade of change. Journal of Public Administration Research and Theory, vol. 15, n.3, jul. 2005, p.353-370.

KERWIN, Cornelius; FURLONG, Scott R. Rulemaking: how government agencies write law and make policy. 5.ed. Thousand Oaks: CQ Press, 2018.

MAGAT, W. A.; KRUPNICK, A. J; HARRINGTON, W. Rules in the Making: a statistical analysis of regulatory agency behavior. RFF Press, 2011.

MANCUSO, W. P. O lobby da indústria no Congresso Nacional: empresariado e política no Brasil contemporâneo. São Paulo: Humanitas/Edusp, 2007.

NAUGHTON, Keith; SCHMID, Celeste; YACKEE, Susan Webb; ZHAN, Xueyong. Understanding commenter influence during agency rule development. Journal of Policy Analysis and Management, vol. 28, n. 2, 2009, p. 258-277.

SALINAS, Natasha S. C.; MARTINS, Fernanda Marques. Os Mecanismos de Participação da Agência Nacional de Saúde Suplementar (ANS). Revista Brasileira de Políticas Públicas, vol. 8, n. 3, dez. 2008. 


\section{SANTOS, M. L. O parlamento sob influência: o lobby da indústria na Câmara} dos Deputados. Tese de Doutorado. Recife: Universidade Federal de Pernambuco. Disponível em: < https://repositorio.ufpe.br/handle/123456789/1484>. Acesso em: 5 out. 2020.

SILVA, Mariana Batista. Mecanismos de participação e atuação de grupos de interesse no processo regulatório brasileiro: o caso da Agência Nacional de Energia Elétrica (Aneel). Revista de Administração Pública, vol. 46, n.4, jul./ago. 2012, p. 969-992.

STIGLER, George. The Theory of Economic Regulation. In: The Citizen and the State: essays on Regulation. Chicago: The University of Chicago Press, 1975.

WEST, William F. Formal Procedures, Informal Process, Accountability, and Responsiveness in Bureaucratic Policymaking: an institutional policy analysis. Public Administration Review, vol. 64, n. 1, 2004, p. 66-88.

YACKEE, J. W.; YACKEE, S. W. A Bias toward business? Assessing Interest Group Influence on the Bureaucracy. Journal of Politics, vol. 68, n.1, 2006, p. 128139.

YACKEE, S. W. Sweet-Talking the Fourth Branch: the influence of interest group comments on Federal Agency Rulemaking. Journal of Public Administration Research and Theory, vol. 16, n.1, 2006, p. 103-124. 